Research Article

\title{
Decision Optimization and Interest Coordination of Dual-Channel Supply Chain Embedded by Two-Echelon Logistics Service Providers under the Dominance of Retailer
}

\author{
Jianjun Zhang $\mathbb{D}^{1,2}$ and Daning Xing $\mathbb{D}^{3}$ \\ ${ }^{1}$ School of Economics and Management, Inner Mongolia Agricultural University, Hohhot 010010, China \\ ${ }^{2}$ School of Economics and Management, Beijing Jiaotong University, Beijing 100044, China \\ ${ }^{3}$ Navigation College, Jimei University, Xiamen 361021, China \\ Correspondence should be addressed to Daning Xing; xingning2002@126.com
}

Received 17 July 2020; Revised 17 October 2020; Accepted 23 October 2020; Published 17 November 2020

Academic Editor: Anna M. Gil-Lafuente

Copyright (c) 2020 Jianjun Zhang and Daning Xing. This is an open access article distributed under the Creative Commons Attribution License, which permits unrestricted use, distribution, and reproduction in any medium, provided the original work is properly cited.

\begin{abstract}
Taking the dual-channel supply chain embedded by two-echelon logistics service providers as the research object, this paper studies the optimal decisions of each decision maker under the centralized and decentralized decision-making mode led by the retailer. Based on the decentralized decision-making mode, an improved coordination mechanism of residual profit sharing is designed to realize the interest coordination, in which the bargaining power of all participants is fully considered. The results show that, under the decentralized decision-making mode, the profit of FLSP increases first and then decreases as the sensitivity coefficient of cross-service level increases, while the profits of other decision makers and the supply chain system decrease with the increase of sensitivity coefficient of cross-service level. The relative size of the price sensitivity coefficient of online and offline channel has an inconsistent impact on the profit of FLSP, while it has a consistent impact on the profits of other decision makers. The profit of FLSP fluctuates greatly with changes in the sensitivity coefficient, and it is difficult to be guaranteed in the entire supply chain system. On this basis, an improved coordination mechanism of residual profit sharing is designed. The results show that, after the introduction of bargaining power coefficient of the Nash negotiation model, the variation coefficient of the profits of all decision makers is smaller after coordination, and the profit growth rates are more uniform.
\end{abstract}

\section{Introduction}

At present, with the rapid development of mobile Internet and e-commerce, consumers' preference for online shopping is gradually increasing, and online retail industry is advancing by leaps and bounds. The Chinese Electronic Commercial Research Centre reported that the transaction scale of China's online retail market has increased from 0.27 trillion yuan in 2009 to 10.32 trillion yuan in 2019, with an average annual growth of $43.96 \%$ (http://www.100EC.CN.) In view of the advantages of online retail channel, such as wide coverage of customers, low operating costs, and realtime continuous interaction with consumers, some retail enterprises give priority to opening up online channel to sell products, such as Netease Strict Selection Company (an online retailer, abbreviated as "Netease"), Xiaomi Co., Ltd (http://www.mi.com), and Three Squirrels Co., Ltd. Due to the asynchronism between product sales and logistics delivery in the sales of physical products through the online channel, the importance of logistics delivery function becomes more and more prominent when orders are generated through the online channel [1]. Moreover, logistics service is an important factor affecting online channel sales and consumer experience [2]. Many scholars have emphasized the importance of logistics service to online retail [3-6], which not only affects the consumer viscosity but also endangers the survival of related enterprises in the whole supply chain. Considering the individualization, diversity, and complexity of logistics service demand in the e-commerce environment, it is difficult for a single logistics service 
enterprise to deal with it due to its limited logistics resources. So, there is an urgent need for Logistics Service Integrator (LSI) with strong resource integration capabilities to better meet the logistics demand of retailers' online channel through integrating Functional Logistics Service Provider (FLSP). Therefore, a supply chain system embedded by twoechelon logistics service providers (including Logistics Service Integrator and Functional Logistics Service Provider) is formed.

However, more and more scholars have gradually realized that, with the emergence of "new retail" in recent years, both online and offline retail have their own advantages. The prospect of offline brick-and-mortar terminals lacking online sales channel is worrisome. Similarly, without the support of offline brick-and-mortar stores, the development momentum of online retail companies will be insufficient [7]. At the same time, in today's consumer upgrading market environment, consumers not only pay attention to products and prices but also value the integrated shopping experience throughout the consumption process, which will prompt more online retailers to actively open offline channels. At this time, the single-channel supply chain embedded by two-echelon logistics service providers has evolved into a dual-channel supply chain.

For example, Netease (an online retailer) established in 2016 purchases products from upstream manufacturers and sells them to online consumers. Its end-to-end logistics service is carried out by Shanghai FineEx Supply Chain Management Co., Ltd (abbreviated as "FineEx"). When a consumer submits an order from the online channel, the FineEx system directly connected to Netease will receive the relevant order information simultaneously. FineEx has established partnership with major regional express companies across the country to jointly meet Netease's B2C logistics service demand by integrating offline storage, transportation capacity, logistics facilities, and other resources. In order to cater to the development trend of "new retail" and better improve consumers' shopping experience, Netease opened an offline experience store in December 2018, implementing the same price strategy of online and offline channel and providing consumers with real and intuitive shopping experience, which forms a dual-channel supply chain system embedded by two-echelon logistics service providers.

However, the increase of the offline channel will lead to certain conflicts between channels, thereby changing the market demand and competition situation of each decision maker under a single channel, which will have a certain impact on the decision of the product price and the service level of upstream and downstream enterprises in the supply chain, and then affects the profits of each decision maker.

Therefore, based on the above observations, this paper mainly discusses the following questions:

(1) As the leader of the supply chain, how does the retailer make the joint decisions of the product retail price and service level? How do manufacturer, LSI, and FLSP respond to this situation?
(2) What effects does the sensitivity coefficient of the online and offline retail price have on the optimal decisions of supply chain?

(3) In order to improve the operation efficiency and maximize the interest of the whole supply chain system, how to scientifically design the interest coordination mechanism and realize the interest coordination of the dual-channel supply chain?

Solving the above important research questions highlights the research objectives and contributions of this paper. As far as the author concerned, this is the first paper that studies the dual-channel supply chain system embedded by two-echelon logistics service providers, discussing the optimal decisions and interest coordination mechanism and exploring the effect of sensitivity coefficient of product retail price for online and offline channels on the optimal decisions and profits of each decision maker.

The remainder of this paper is organized as follows. In Section 2, this paper briefly reviews the relevant literature, and this paper introduces notation and assumptions of the modeling framework in Section 3. Section 4 analyzes the optimal decisions in different decision-making modes, and numerical examples are provided in Section 4 to illustrate the results. Three different interest coordination models and numerical examples are provided in Section 5 to realize the interest coordination of the supply chain. The conclusions and some possible directions of future research are arranged in Section 6.

\section{Literature Review}

When retailers open the offline channel on the basis of the online channel, the single-channel supply chain system embedded by two-echelon logistics service providers has evolved into a dual-channel supply chain. Due to the existence of channel conflicts in the dual-channel supply chain, it will lead to a series of management problems, which will affect the optimal decisions and profits of decision makers in the whole supply chain. Therefore, there is an urgent need for decision-making optimization and interest coordination.

Based on the aspect of optimal decision in the dualchannel supply chain, most scholars have studied the channel selection decision, pricing decision, order quantity decision, and optimal service level decision under the conditions of reference price effect, consumer free-riding, uncertain demand, information asymmetry, risk attitude and carbon emission constraints, etc.

For example, Yan et al. [8] study the necessary conditions for dual-channel supply chains to exist in an e-commerce environment and analyze the price decisions of dualchannel supply chains. Zhang et al. [9] analyze a retailer's channel structure choice in a supply chain with a retailer and a manufacturer; the results show that when the customer acceptance rate for the online channel is medium, the retailer's optimal channel structure is dual channels. On this basis, Zhang et al. [10] study the "preorder-online, pickupin-store" strategy (POPU) for a dual-channel retailer; the results show that the POPU strategy decreases the retailer's 
market share and profits. Liu et al. [11] construct a dualchannel supply chain consisting of the manufacturer and retailer and study the impact of retailer's alliance decisions on the profits of the manufacturer and the entire supply chain when the manufacturer opens an online channel. Lin and Wang [12] research the impact of consumer channel preferences and brand competition on manufacturer's sales channel choices, pricing, and product quality levels. Cao et al. [13] analyze the impact of consumer free-riding degree on retailer's optimal order quantity decision in the dualchannel supply chain. Zhou et al. [14] study the manufacturer-led price decisions of dual-channel supply chains in case of asymmetric market demand information. Yan et al. [15] research the impact of manufacturer's concealed cost information on optimal decisions in dual-channel supply chains. Ren et al. [16] analyze the optimal price decisions in dual-channel supply chain models; the price and service competition between the dual channels is considered in the models. He et al. [17] analyze the inventory and pricing decisions in a dual-channel supply chain with deteriorating products.

On the basis of the above research results, Zhang et al. [18] construct a dual-channel closed-loop supply chain and study the optimal retail price and retail service level decisions in the supply chain. He et al. [19] explore channel structure and pricing decisions of the manufacturer in a dual-channel closed-loop supply chain; the logistics service level is not considered in the model. Wang et al. [20] construct a dual-channel supply chain consisting of two manufacturing firms and one retailer and research the product price decisions and service level decisions using complementary products produced by the two firms as examples. Ranjan and Jha [21] construct a manufacturer's dual-channel supply chain and study the product price and service level decisions, where green and nongreen products are sold between channels. And the demand for different types of products is affected by the green quality level and sales effort level, respectively. Liu et al. [22] further consider the product retail price decisions between channels in the case where the manufacturer and retailer have both dual channels. However, none of the above studies have dealt with the integrated decisions of different service levels, product retail prices, and logistics service prices in dualchannel supply chains, nor have they considered the importance of logistics service providers' participation in dualchannel supply chain operations.

On the interest coordination of the dual-channel supply chain, Pu et al. [23] construct a manufacturer's dual-channel supply chain and find that consumer free-riding degree has a negative impact on the retailer's effort level and total supply chain profit. On this basis, a revenue sharing contract is designed to improve the effort level in the decentralized decision mode. Kong et al. [24] research a dual-channel closed-loop supply chain based on the optimal price and after-sales service level decision in the centralized and decentralized decision mode and design a revenue sharing contract to achieve a Pareto improvement. Yu and Ren [25] study the impact of information services on optimal pricing in a dual-channel supply chain and design a quantity discount contract to achieve supply chain coordination. Subrata [26] designs a price discount contract from upstream to downstream to realize the coordination of the three-level dual-channel supply chain. Zheng et al. [27] design a revised two-part contract to achieve interest coordination of the closed-loop dual-channel supply chain. Zhou et al. [28] design a cost sharing contract for the manufacturer to increase the service level of the entire supply chain and the profit of various decision makers by sharing the retailer's service cost in a consumer free-riding scenario. Amin and Jafar [29] construct a channel transfer price agreement to achieve supply chain coordination based on a manufacturer-led dual-channel supply chain. He et al. [30] establish a dual-channel model which consists of a manufacturer and an online shop owned by a manufacturer and a retailer, and design a transshipment price mechanism to coordinate the supply chain.

From the above literature review, we can see that most of the existing literatures are based on manufacturer-led dualchannel supply chain to study the optimal decision and interest coordination of product price and service level, while few research studies focus on the construction of the dual-channel supply chain for retailers. At the same time, in the research of the dual-channel supply chain, few scholars put the logistics service providers and logistics service level into the model for research, and they have insufficient understanding of the importance of logistics service provider's participation in dual-channel supply chain. In addition, in the research on decision optimization and interest coordination of the dual-channel supply chain, most scholars mainly focus on two-echelon or three-echelon supply chain, while there are few studies on four-echelon dual-channel supply chain. It is true that coordinating a four-echelon supply chain is more difficult than coordinating a two-echelon or three-echelon supply chain.

In response to the reality of multilevel outsourcing in China's logistics industry, combined with the development trend of "new retail," a dual-channel supply chain structure model embedded by two-echelon logistics service providers is built, which is a four-echelon dual-channel supply chain. This paper studies the optimal decisions of the product retail price, logistics service level, and offline comprehensive experience service level of the whole dual-channel supply chain system led by the retailer in centralized and decentralized decision-making mode. And it designs an improved residual profit sharing coordination mechanism to realize the interest coordination of the dual-channel supply chain.

\section{Conceptual Model and Research Assumptions}

3.1. Conceptual Model. Combined with the actual operation background of the dual-channel supply chain embedded by two-echelon logistics service providers, the conceptual model is constructed, as shown in Figure 1.

The structure diagram of the dual-channel supply chain in Figure 1 includes a Product Supply Chain (PSC) consisting of the manufacturer and retailer and a Logistics Service Supply Chain (LSSC) consisting of Logistics Service 


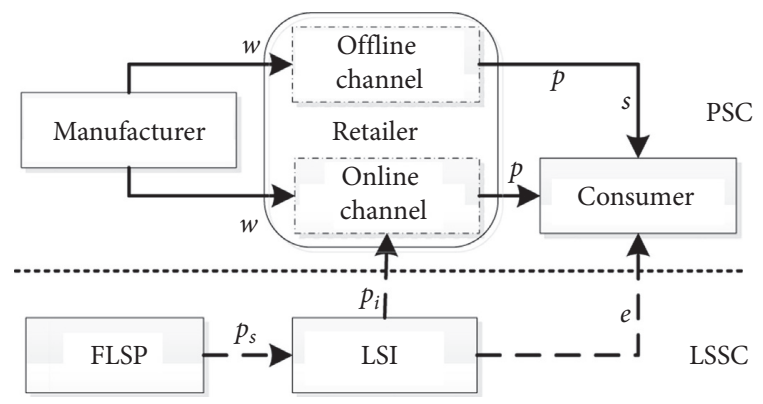

FIGURE 1: Structure diagram of the dual-channel supply chain embedded by two-echelon logistics service providers.

Integrator (LSI) and Functional Logistics Service Provider (FLSP). The retailer has opened up the offline retail channel based on its online channel, and its offline channel can provide consumers with the experience service level, which is called "offline comprehensive experience service level," which attracts consumers by providing high-level offline comprehensive experience services.

Suppose that, before the sales season, the retailer places an order with quantity $d$ to the upstream manufacturer based on customer demand, and the manufacturer produces products according to the order of the retailer and then sells products to the retailer according to the unit wholesale price $w$. After that, consumers can purchase the products from the retailer at retail price $p$ through either the online channel or the offline channel, and the logistics service for the online channel is provided by two-echelon logistics service providers consisting of LSI and FLSP. Products sold through the offline channel need to be picked up by consumers themselves, but the offline channel can provide consumers with offline comprehensive experience service. The unit logistics service sale price that the retailer has to pay to LSI is $p_{i}$, and the unit logistics service order price that LSI needs to pay to FLSP is $p_{s}$, obviously $p_{i}>p_{s}$. Logistics service level provided by FLSP is $e$. Consumers can make a comprehensive decision on their purchase channel and volume based on the product retail price, logistics service level, and offline comprehensive experience service level.

\subsection{Research Assumptions}

(1) Without losing generality, in order to make the above model conform to the reality, the parameters and variables in Table 1 should meet the following conditions: $0<c_{m}<w<p, 0<c_{s}<p_{s}<p_{i}<p$, and $w+p_{i}<p$. This ensures nonnegative profits for all decision makers in the supply chain.

(2) Suppose that the manufacturer's production capacity is unlimited, and there is no shortage of goods in the dual-channel supply chain. The products sold by the retailer through online and offline channels are completely homogeneous, and the information of four decision makers is symmetric.

(3) It is assumed that the investment, construction, and operation costs of the retailers' offline channel, such as physical stores, are ultimately reflected in the improvement of consumers' offline comprehensive experience service level, that is, the higher the level of consumers' offline comprehensive experience service is, the higher the comprehensive cost of retailers' offline channel is. Following the research design of most scholars, this paper assumes that the cost of offline comprehensive experience is as follows: $c(s)=\left(s^{2} / 2\right)$. Compared with the investment and construction costs of offline physical stores, the operation and maintenance costs of online channels are relatively small or even negligible. And the main cost is the logistics service price expenditure, that is, the logistics service price $p_{i}$ paid by the retailer to LSI.

(4) In the wake of "new retail," the retailer gradually becomes larger and plays a dominant role in the entire supply chain. The large retailer is often the leader in the supply chain [9]. There are some retailers who enjoy sufficient power to be the channel leader because of their large size compared to manufacturers and their ability to economically sell products with a reasonable profit margin [31]. It is assumed in this paper that the retailer plays an essential role in the entire dual-channel supply chain. It not only determines the retail price of products but also determines the sales price of logistics service. This highlights the dominant position of the retailer in the whole supply chain driven by "new retail."

(5) It is assumed that in a dual-channel supply chain embedded by two-echelon logistics service providers, there is competition between the online and offline channel around the level of logistics service and offline comprehensive experience service. The level of logistics service includes not only the quality of logistics service but also the waiting time of logistics delivery and a higher logistics service level means lower product's deterioration/damage or shorter logistics time [32]. Since the retail price of products in online and offline channels are the same, the online and offline channel will compete fiercely with the service level. The high-level service of one channel will not only improve the market demand of its own channel but also reduce the market demand of another channel.

\section{Optimal Decision Analysis in Different Decision-Making Modes}

This paper constructs the game model under the centralized and decentralized decision-making mode around the structure diagram of dual-channel supply chain, the related symbols, and their meanings are illustrated in Table 1. Among them, centralized decision is represented by superscript $c$, decentralized decision is represented by superscript $d$, and optimal decision is represented by superscript * . 
TABLE 1: Related symbols and variables in the dual-channel supply chain model.

\begin{tabular}{|c|c|}
\hline Symbols & Implication \\
\hline$c_{m}$ & Marginal production cost of manufacturer \\
\hline$c_{s}$ & Marginal logistics cost of FLSP \\
\hline$e$ & Logistics service level \\
\hline$d$ & Product demand \\
\hline$k$ & Sensitivity coefficient of logistics service level \\
\hline$\lambda$ & Sensitivity coefficient of offline comprehensive experience service level \\
\hline$a$ & Market capacity \\
\hline$\theta$ & Consumer preference for online channel \\
\hline$d_{o}$ & Online channel market demand \\
\hline$d_{f}$ & Offline channel market demand \\
\hline$\Pi_{m}$ & Profit function of manufacturer \\
\hline$\Pi_{i}$ & Profit function of LSI \\
\hline$\Pi_{p}$ & Profit function of PSC \\
\hline$w^{P}$ & Product wholesale price \\
\hline$p_{i}$ & Logistics service sale price \\
\hline$p_{s}$ & Logistics service order price \\
\hline$p$ & Product retail price \\
\hline$\beta_{1}$ & Sensitivity coefficient of online channel retail price \\
\hline$\beta_{2}$ & Sensitivity coefficient of offline channel retail price \\
\hline$\mu_{1}$ & Sensitivity coefficient of online channel cross-service level \\
\hline$\mu_{2}$ & Sensitivity coefficient of offline channel cross-service level \\
\hline$\Pi_{r}$ & Profit function of retailer \\
\hline$\Pi_{r l}$ & Total profit function of retailer and LSSC \\
\hline$\Pi_{s}$ & Profit function of FLSP \\
\hline$\Pi_{l}$ & Profit function of LSSC \\
\hline$\Pi$ & Profit function of the supply chain \\
\hline
\end{tabular}

In the dual-channel supply chain, the products sold by the retailer through the online channel mainly meet the needs of consumers through LSSC, while the products in offline channels are sold mainly by customers coming to the store for experience and taking them by themselves. Dumrongsiri et al. [33] show that the channel service level has a significant impact on consumer choice and customer demand, so this paper hypothesizes that product demand is affected by the combination of logistics service level $e$, offline comprehensive experience service level $s$, and product retail price $p$. The product demand functions of online and offline channels are as follows:

$$
\begin{aligned}
& d_{o}=\theta a-\beta_{1} p+k e-\mu_{1} s \\
& d_{f}=(1-\theta) a-\beta_{2} p+\lambda s-\mu_{2} e \\
& d=d_{o}+d_{f}=a-\left(\beta_{1}+\beta_{2}\right) p+\left(k-\mu_{2}\right) e+\left(\lambda-\mu_{1}\right) s .
\end{aligned}
$$

Based on $d_{o} \geq 0$ and $d_{f} \geq 0$, it can be concluded that $w+$ $p_{i} \leq p \leq \min \left\{\left(\left(\theta a+k e-\mu_{1} s\right) / \beta_{1}\right),\left(\left((1-\theta) a+\lambda s-\mu_{2} e\right) / \beta_{2}\right)\right.$ \} , in which $d_{o}$ and $d_{f}$ represent product demand in online and offline channel and $d$ represents the total demand of dual-channel supply chain. $\beta_{1}$ and $\beta_{2}$ are the product retail price sensitivity coefficients of online and offline channels, respectively. In the "new retail" era, the prices of online and offline channels (referred to as "online and offline") tend to be the same $[29,34]$. And in the dual-channel supply chain, in order to alleviate the channel conflict, about $2 / 3$ of the enterprises choose the same price strategy of online and offline channels [35], so this paper also assumes that the online and offline channels have the same price. However, due to the different channel preferences and utility of consumers, their sensitivity to the retail price of online and offline channel is not completely consistent $[23,24,36]$, that is to say, there may be a situation of $\beta_{1}>\beta_{2}$ or $\beta_{1}<\beta_{2}$.

The offline comprehensive experience service level $s$ mainly reflects the comprehensive experience of consumers caused by the offline channel. If it is higher, it means that the consumer experience of the offline channel is good, if it is low, it means that the consumer experience of the offline channel is poor. The offline comprehensive experience service level will directly affect the market demand of the offline channel. $\lambda$ stands for the sensitivity coefficient of offline comprehensive experience service level, reflecting the sensitivity of the offline comprehensive experience service level to market demand. $\mu_{1}$ and $\mu_{2}$ are the sensitivity coefficients of cross-service level between the two channels, online and offline, respectively, where $0<\mu_{2}<k$ and $0<\mu_{1}<\lambda$ indicate that the cross-effect of the service level brought by the competitive channel is smaller than that of its own channel on demand.

For simplicity, referring to the research design of Zhou et al. [28] and Mukhopadhyay et al. [37], the following equation holds $\mu_{1}=\mu_{2}=\mu$, in other words, the service level of online/offline channels has a consistent cross-influence on the market demand of offline/online channels. The total profit functions of the retailer, manufacturer, LSI, FLSP, PSC, LSSC, and supply chain are obtained as follows: manufacturer, retailer, LSI, FLSP, PSC, and LSSC are represented by subscript $m, r, i, s, p$, and $l$, respectively.

Profit function of the retailer: 


$$
\begin{aligned}
\Pi_{r}= & {\left[a-\left(\beta_{1}+\beta_{2}\right) p+(k-\mu) e+(\lambda-\mu) s\right](p-w) } \\
& -\left(\theta a-\beta_{1} p+k e-\mu s\right) p_{i}-\frac{1}{2} s^{2} .
\end{aligned}
$$

Profit function of the manufacturer:

$\Pi_{m}=\left[a-\left(\beta_{1}+\beta_{2}\right) p+(k-\mu) e+(\lambda-\mu) s\right]\left(w-c_{m}\right)$.

Profit function of LSI:

$$
\Pi_{i}=\left(\theta a-\beta_{1} p+k e-\mu s\right)\left(p_{i}-p_{s}\right) .
$$

Profit function of FLSP:

$$
\Pi_{s}=\left(\theta a-\beta_{1} p+k e-\mu s\right)\left(p_{s}-c_{s}\right)-\frac{1}{2} e^{2} .
$$

Profit function of PSC:

$$
\begin{aligned}
\Pi_{p}= & {\left[a-\left(\beta_{1}+\beta_{2}\right) p+(k-\mu) e+(\lambda-\mu) s\right]\left(p-c_{m}\right) } \\
& -\left(\theta a-\beta_{1} p+k e-\mu s\right) p_{i}-\frac{1}{2} s^{2} .
\end{aligned}
$$

Profit function of LSSC:

$$
\Pi_{l}=\left(\theta a-\beta_{1} p+k e-\mu s\right)\left(p_{i}-c_{s}\right)-\frac{1}{2} e^{2} .
$$

Total profit function of the supply chain system:

$$
\begin{aligned}
\Pi= & \left(\theta a-\beta_{1} p+k e-\mu s\right)\left(p-c_{s}-c_{m}\right) \\
& +\left[(1-\theta) a-\beta_{2} p+\lambda s-\mu_{2} e\right]\left(p-c_{m}\right)-\frac{1}{2} s^{2}-\frac{1}{2} e^{2} .
\end{aligned}
$$

4.1. Centralized Decision-Making Mode. The centralized decision-making mode takes the profit maximization of the entire supply chain system as the objective, calculating the optimal product retail price $p$, logistics service level $e$, and offline comprehensive experience service level $s$. Firstly, take the second-order partial derivatives of the total profit function of the supply chain system with respect to $p, e$, and $s$. The Hessian matrix is as follows:

$$
\begin{aligned}
& H(p, e, s)=\left[\begin{array}{lll}
\frac{\partial^{2} \Pi}{\partial p^{2}} & \frac{\partial^{2} \Pi}{\partial p \partial e} & \frac{\partial^{2} \Pi}{\partial p \partial s} \\
\frac{\partial^{2} \Pi}{\partial e \partial p} & \frac{\partial^{2} \Pi}{\partial e^{2}} & \frac{\partial^{2} \Pi}{\partial e \partial s} \\
\frac{\partial^{2} \Pi}{\partial s \partial p} & \frac{\partial^{2} \Pi}{\partial s \partial e} & \frac{\partial^{2} \Pi}{\partial s^{2}}
\end{array}\right]=\left[\begin{array}{ccc}
-2\left(\beta_{1}+\beta_{2}\right) & k-\mu & \lambda-\mu \\
k-\mu & -1 & 0 \\
\lambda-\mu & 0 & -1
\end{array}\right], \\
& D_{1}=-\left(-2\left(\beta_{1}+\beta_{2}\right)\right)=2\left(\beta_{1}+\beta_{2}\right)>0 \text {, } \\
& D_{2}=\left|\begin{array}{cc}
-2\left(\beta_{1}+\beta_{2}\right) & k-\mu \\
k-\mu & -1
\end{array}\right|=2\left(\beta_{1}+\beta_{2}\right)-(k-\mu)^{2}>0, \\
& D_{3}=-\left|\begin{array}{ccc}
-2\left(\beta_{1}+\beta_{2}\right) & k-\mu & \lambda-\mu \\
k-\mu & -1 & 0 \\
\lambda-\mu & 0 & -1
\end{array}\right|=2\left(\beta_{1}+\beta_{2}\right)-(k-\mu)^{2}-(\lambda-\mu)^{2}>0 .
\end{aligned}
$$

When the above conditions are met, the optimal solutions can be obtained.

According to $(\partial \Pi / \partial e)=0, \quad(\partial \Pi / \partial s)=0, \quad$ and $(\partial \Pi / \partial p)=0$, it can be concluded that

$$
\begin{aligned}
& e(p)=(k-\mu)\left(p-c_{m}\right)-k c_{s}, \\
& s(p)=(\lambda-\mu)\left(p-c_{m}\right)+\mu c_{s},
\end{aligned}
$$

$$
p(s, e)=\frac{a+(k-\mu) e+(\lambda-\mu) s+\left(\beta_{1}+\beta_{2}\right) c_{m}+\beta_{1} c_{s}}{2\left(\beta_{1}+\beta_{2}\right)}
$$

Solving (12)-(14) simultaneously, the optimal product retail price, logistics service level, and offline comprehensive experience service level under centralized decision-making mode can be obtained as follows: 


$$
\begin{aligned}
& p^{c *}=\frac{a-c_{m}\left[(k-\mu)^{2}+(\lambda-\mu)^{2}-\beta_{1}-\beta_{2}\right]+c_{s}\left[\mu(\lambda-\mu)-k(k-\mu)+\beta_{1}\right]}{2\left(\beta_{1}+\beta_{2}\right)-(k-\mu)^{2}-(\lambda-\mu)^{2}}, \\
& e^{c *}=(k-\mu) \frac{a-\left(\beta_{1}+\beta_{2}\right) c_{m}+c_{s}\left[\mu(\lambda-\mu)-k(k-\mu)+\beta_{1}\right]}{2\left(\beta_{1}+\beta_{2}\right)-(k-\mu)^{2}-(\lambda-\mu)^{2}}-k c_{s}, \\
& s^{c *}=(\lambda-\mu) \frac{a-\left(\beta_{1}+\beta_{2}\right) c_{m}+c_{s}\left[\mu(\lambda-\mu)-k(k-\mu)+\beta_{1}\right]}{2\left(\beta_{1}+\beta_{2}\right)-(k-\mu)^{2}-(\lambda-\mu)^{2}}+\mu c_{s} .
\end{aligned}
$$

Substituting (15)-(17) into (1)-(3), the optimal online channel demand, offline channel demand, and total supply chain demand can be obtained as follows:

$$
\begin{aligned}
& d_{o}^{c *}=\theta a-\beta_{1} p^{c *}+k e^{c *}-\mu s^{c *}, \\
& d_{f}^{c *}=(1-\theta) a-\beta_{2} p^{c *}+\lambda s^{c *}-\mu e^{c *} \\
& d^{c *}=\frac{\left(a\left(\beta_{1}+\beta_{2}\right)-\left(\beta_{1}+\beta_{2}\right)^{2} c_{m}-\beta_{2} c_{s}\left[k(k-\mu)-\mu(\lambda-\mu)+\beta_{1}\right]-\beta_{1} c_{s}\left[\mu(k-\mu)-\lambda(\lambda-\mu)+\beta_{1}\right]\right)}{2\left(\beta_{1}+\beta_{2}\right)-(k-\mu)^{2}-(\lambda-\mu)^{2}} .
\end{aligned}
$$

Substituting (14)-(16) into (10), the optimal profit function is as follows:

$$
\Pi^{c *}=d^{c *}\left(p^{c *}-w^{c *}\right)-d_{o}^{c *} c_{s}-\frac{1}{2}\left(s^{c *}\right)^{2}-\frac{1}{2}\left(e^{c *}\right)^{2}
$$

Proposition 1. When the sensitivity coefficients $\beta_{1}$ and $\beta_{2}$ of the product retail price and the total market capacity a change if the decision maker increases the level of offline comprehensive experience service or logistics service, it will also increase the product retail price to increase the profit of the entire supply chain.

Proof. Since $p^{c *}=(1 / \lambda-\mu) s^{c *}+c_{m}-(\mu / \lambda-\mu) c_{s}$, the following equation holds when $\beta_{1}$ and $\beta_{2}$ and $a$ vary: $\left(\mathrm{d} p^{c *} /\right.$ $\mathrm{d} x)=\left(\partial p^{c *} / \partial s^{c *}\right)\left(\mathrm{d} s^{c *} / \mathrm{d} x\right)+(\mathrm{d} A / \mathrm{d} x)=(1 / \lambda-\mu)\left(\mathrm{d} s^{c *} /\right.$ $\mathrm{d} x)$, where $k, \beta_{1}, \beta_{2}$, and $a$ can be denoted by $x$, $A=c_{m}-(\mu / \lambda-\mu) c_{s}$, that is, $\Delta p^{c *}=(1 / \lambda-\mu) \Delta s^{c *}$, since $\lambda>\mu,(1 / \lambda-\mu)>0$. Thus, when the offline comprehensive experience service level increases, so does the product retail price.

Similarly, we have $p^{c *}=(1 / k-\mu) e^{c *}+c_{m}+(k / k-\mu) c_{s}$. So, when $\beta_{1}$ and $\beta_{2}$ and $a$ vary, the following equation holds: $\left(\mathrm{d} p^{c *} / \mathrm{d} x\right)=\left(\partial p^{c *} / \partial e^{c *}\right)\left(\mathrm{d} e^{c *} / \mathrm{d} x\right)+(\mathrm{d} B / \mathrm{d} x)=(1 / k-$ $\mu)\left(\mathrm{d} e^{c *} / \mathrm{d} x\right)$, where $B=c_{m}+(k / k-\mu) c_{s}$. That is to say $\Delta p^{c *}=(1 / k-\mu) \Delta e^{c *}$, due to $k>\mu,(1 / k-\mu)>0$. Therefore, when logistics service level increases, the product retail price will also increase.

Proposition 2. The price elasticity of the logistics service level is greater than 1, while the price elasticity of offline comprehensive experience service level changes with the relative size of $\mu c_{s}$ and $(\lambda-\mu) c_{m}$, if $\mu c_{s}<(\lambda-\mu) c_{m}, \varepsilon_{s p}>1$; if $\mu c_{s}=(\lambda-\mu) c_{m}, \varepsilon_{s p}=1$; if $\mu c_{s}>(\lambda-\mu) c_{m}, \varepsilon_{s p}<1$.

Proof. The price elasticity of logistics service level is $\varepsilon_{\text {ep }}=$ $((\Delta e / e) /(\Delta p / p))=\left(\left((k-\mu) p^{c *}\right) /\left((k-\mu)\left(p^{c *}-c_{m}\right)-k c_{s}\right)\right)$, since $(k-\mu) p^{c *}>(k-\mu)\left(p^{c *}-c_{m}\right)-k c_{s}$; therefore, $\left(\varepsilon_{\mathrm{ep}}>1\right)$, and the price elasticity of the logistics service level is greater than 1 , which indicates that the logistics service level is full of price elasticity.

The price elasticity of the offline comprehensive experience service level is $\varepsilon_{\mathrm{sp}}=((\Delta s / s) /(\Delta p / p))=\left((\lambda-\mu) p^{c *} /\right.$ $\left.(\lambda-\mu)\left(p^{c *}-c_{m}\right)+\mu c_{s}\right)$ if $\mu c_{s}<(\lambda-\mu) c_{m}$, then $(\lambda-$ $\mu) p^{c *}>(\lambda-\mu)\left(p^{c *}-c_{m}\right)+\mu c_{s}, \varepsilon_{\mathrm{sp}}>1$. Similarly, it can be proved that if $\mu c_{s}=(\lambda-\mu) c_{m}$, then $\varepsilon_{\mathrm{sp}}=1$; if $\mu c_{s}>(\lambda-\mu) c_{m}$, then $\varepsilon_{s p}<1$. So, if $\lambda$ increases, then $\varepsilon_{s p}$ increases; if $\lambda$ decreases, then $\varepsilon_{s p}$ also decreases. This indicates that the more sensitive consumers are to the offline comprehensive experience service level, the greater the price elasticity of it will be.

As the logistics service level is elastic in price, compared with improving the logistics service level when the product retail price is low, the decision maker of the supply chain has the power to improve the offline comprehensive experience service level.

Proposition 3. In centralized decision-making mode, the logistics service level increases with the increase of sensitivity coefficient $\lambda$ and its own sensitivity coefficient $k$. The offline comprehensive experience service level increases with the increase of sensitivity coefficient $k$ and its own sensitivity coefficient $\lambda$.

Proof. Since $e^{c *}>0$ and $s^{c *}>0$, according to the expression of $e^{c *}$, it can be proved that $\left(\partial e^{c *} / \partial \lambda\right)>0,\left(\partial e^{c *} / \partial k\right)>0$, that 
is, the logistics service level increase with $\lambda$ and $k$. The following formula can also be proved: $\left(\partial s^{c *} / \partial k\right)>0$, $\left(\partial s^{c *} / \partial \lambda\right)>0$. That is, the logistics service level and the offline comprehensive experience service level are both influenced by their own sensitivity coefficients and the sensitivity coefficients of the service level of the other channel. This also indicates that there is a competition between online and offline channels around the service level.

Proposition 4. In the centralized decision-making mode, the optimal product retail price decreases with the increase of sensitivity coefficient $\beta_{1}$ and $\beta_{2}$ of product retail price and increases with the increase of sensitivity coefficient $k$ and $\lambda$.

Proof. $\left(\partial p^{*} / \partial \beta_{1}\right)=\left(\left(\left(c_{m}+c_{s}\right)\left[2\left(\beta_{1}+\beta_{2}\right)-(k-\mu)^{2}-(\lambda-\right.\right.\right.$ $\left.\mu)^{2}\right]-2\left[a-c_{m}\left[(k-\mu)^{2}+(\lambda-\mu)^{2}-\beta_{1}-\beta_{2}\right]+c_{s}[\mu(\lambda-\mu)-\right.$ $\left.\left.\left.\left.k(k-\mu)+\beta_{1}\right]\right]\right) /\left[2\left(\beta_{1}+\beta_{2}\right)-(k-\mu)^{2}-(\lambda-\mu)^{2}\right]^{2}\right)$, combined with $2\left(\beta_{1}+\beta_{2}\right)-(k-\mu)^{2}-(\lambda-\mu)^{2}>0$ and $e^{c *} \geq 0$, and we have $\left(2 k a-\beta_{2}\left(2 k c_{m}+4 k c_{s}-2 \mu c_{m}-2 \mu c_{s}\right)-\right.$ $\beta_{1}\left(2 k c_{m}+2 k c_{s}-2 \mu c_{m}\right)-\mu\left[c_{s}(k+\lambda)^{2}+2 a\right]+2 k c_{s} \quad\left(\lambda^{2}+\right.$ $\left.\left.\mu^{2}\right)\right)>0$, combined with the above expressions, and we can prove $\left(\partial p^{c *} / \partial \beta_{1}\right)<0$; in the same way, we can prove $\left(\partial p^{c *} / \partial \beta_{2}\right)<0$.

Similarly, since $e^{c *} \geq 0$, we have $\left((k-\mu)\left[a-\left(\beta_{1}+\beta_{2}\right) c_{m}+\right.\right.$ $\left.c_{s}\left[\mu(\lambda-\mu)-k(k-\mu)+\beta_{1}\right]\right]-\quad k c_{s}\left[2\left(\beta_{1}+\beta_{2}\right)-(k-\mu)^{2}-\right.$ $\left.\left.(\lambda-\mu)^{2}\right]\right)>0$, combined with the expression of $\left(\partial p^{c *} / \partial k\right)$, and we can get $\left(\partial p^{c *} / \partial k\right)>0$. In the same way, since $s^{c *} \geq 0$, we get $\left((\lambda-\mu)\left[a-\left(\beta_{1}+\beta_{2}\right) c_{m}+c_{s}[\mu(\lambda-\mu)-k(k-\mu)+\right.\right.$ $\left.\left.\left.\beta_{1}\right]\right]+\mu c_{s}\left[2\left(\beta_{1}+\beta_{2}\right)-(k-\mu)^{2}-(\lambda-\mu)^{2}\right]\right)>0$, and combined with the expression of $\left(\partial p^{c *} / \partial \lambda\right)$, we get $\left(\partial p^{c *} / \partial \lambda\right)>0$.

In other words, when the sensitivity coefficient of logistics service level and offline comprehensive experience service level increase, combined with Proposition 3, it can be concluded that both the logistics service level and offline comprehensive experience service level are improved, and combined with the conclusion of Proposition 1, it can be concluded that the product retail price will increase at the same time.

Proposition 5. In the centralized decision-making mode, the optimal product retail price, logistics service level, and offline comprehensive experience service level all decrease with the increase of sensitivity coefficient $\mu$.

Proof. Because $\mu<k$ and $\mu<\lambda$, so $\mu<(k+\lambda / 2)$; according to $\left(2 k a-\beta_{2}\left(2 k c_{m}+4 k c_{s}-2 \mu c_{m}-2 \mu c_{s}\right)-\beta_{1}\left(2 k c_{m}+2 k c_{s}-\right.\right.$ $\left.\left.2 \mu c_{m}\right)-\mu\left[c_{s}(k+\lambda)^{2}+2 a\right]+2 k c_{s}\left(\lambda^{2}+\mu^{2}\right)\right)>0$, we have $\left(\partial p^{c *} / \partial \mu\right)<0$.

In the same way, combined with $e^{c *} \geq 0, s^{c *} \geq 0$, and $d^{c *} \geq 0$, it can be proved that $\left(\partial e^{c *} / \partial \mu\right)<0$ and $\left(\partial s^{c *} / \partial \mu\right)<0$.

It can be seen that the greater the sensitivity coefficient of the cross-service level between online and offline channels, the more intense the competition of service level between channels. At this time, in order to expand product demands and improve the profit of the whole supply chain, it is necessary to gradually reduce the retail price of products.

At the same time, due to the fierce competition of the service level between different channels, in order to alleviate the erosion of competition on the whole supply chain profits, the retailer who adopts centralized decision-making mode will tend to gradually reduce the service level.

Proposition 6. Under the centralized decision-making mode, the level of offline comprehensive experience service and logistics service decreases with the increase of sensitivity coefficient $\beta_{1}$ and $\beta_{2}$.

Proof. Based on the relationship between $\Delta p^{c *}, \Delta e^{c *}$, and $\Delta s^{c *}$ in Proposition 1, combined with the research conclusions of Proposition 4 , we can get the conclusions: $\left(\partial e^{c *} / \partial \beta_{1}\right)<0, \quad\left(\partial e^{c *} / \partial \beta_{2}\right)<0, \quad\left(\partial s^{c *} / \partial \beta_{1}\right)<0, \quad$ and $\left(\partial s^{c *} / \partial \beta_{2}\right)<0$.

When the sensitivity coefficient of the product retail price increases, consumers are more sensitive to the product price compared with the service level. In other words, the improvement of the service level cannot contribute to the ideal profit level, so, the decision maker of the supply chain will gradually reduce the service level.

Proposition 7. In the centralized decision-making mode, the product retail price, the level of logistics service and offline comprehensive experience service, and the market demand all increase with the market capacity a.

Proof. Due to $2\left(\beta_{1}+\beta_{2}\right)-(k-\mu)^{2}-(\lambda-\mu)^{2}>0$, according to the expressions of $p^{c *}, e^{c *}, s^{c *}$, and $d^{c *}$, we can $\operatorname{get}\left(\partial p^{c *} / \partial a\right)=\left(1 /\left(2\left(\beta_{1}+\beta_{2}\right)-(k-\mu)^{2}-(\lambda-\mu)^{2}\right)\right)>0$, $\left(\partial e^{c *} / \partial a\right)=\left(k-\mu / 2\left(\beta_{1}+\beta_{2}\right)-(k-\mu)^{2}-(\lambda-\mu)^{2}\right)>0$, $\left(\partial s^{c *} / \partial a\right)=\left(\lambda-\mu / 2\left(\beta_{1}+\beta_{2}\right)-(k-\mu)^{2}-(\lambda-\mu)^{2}\right)>0$, and $\left(\partial d^{c *} / \partial a\right)=\left(\beta_{1}+\beta_{2} / 2\left(\beta_{1}+\beta_{2}\right)-(k-\mu)^{2}-(\lambda-\right.$ $\left.\mu)^{2}\right)>0$.

In other words, with the expansion of the market capacity, the decision maker of the dual-channel supply chain system has the enthusiasm to improve the logistics service level and the offline comprehensive experience service level in order to better meet the needs of customers. On this basis, decision maker will also increase the retail price simultaneously in order to make up for the loss of service cost caused by the improvement of the service level.

Proposition 8. In the centralized decision-making mode, when $k \leq \lambda$, the logistics service level is less than the offline comprehensive experience service level; if $c_{s}=0$ and $k>\lambda$, the logistics service level is greater than the offline comprehensive experience service level.

Proof. When $k \leq \lambda$, it can be shown from the expressions $e^{c *}$ and $s^{c *}$ that $e^{c *}<s^{c *}$, when $c_{s}=0$ and $k>\lambda$ and $e^{c *}>s^{c *}$. In other words, when the sensitivity coefficient of the logistics service level is low, the improvement of the logistics service level will reduce the contribution to the total profit of the supply chain, and the decision maker should reduce the logistics service level. Conversely, when the sensitivity coefficient of the offline comprehensive experience service level is large, it shows that the improvement of the offline comprehensive experience service level can increase the 
profit of the whole supply chain faster, so its service level will be improved.

Therefore, in centralized decision-making mode, the decision maker of the supply chain will decide the level of logistics service and offline comprehensive experience service according to the relative size of the consumer service level sensitivity coefficient.

\subsection{Decentralized Decision-Making Mode}

4.2.1. Model Calculation. The decision order in the decentralized decision-making mode is as follows: the retailer first needs to decide the product retail price $p$, the sales price $p_{i}$ of logistics service, and the offline comprehensive experience service level $s$. Then, LSI decides the order price $p_{s}$ of logistics service and the manufacturer decides the product wholesale price $w$. Finally, FLSP decides the logistics service level $e$.

First, the derivative of $\Pi_{s}$ to $e$ is obtained by the inverse induction method; since $\left(\partial^{2} \Pi_{s} / \partial e^{2}\right)=-1<0$, making $\left(\partial \Pi_{s} / \partial e\right)=0$, we obtain

$$
e\left(p_{s}\right)=k\left(p_{s}-c_{s}\right)
$$

Substituting (20) into $\Pi_{i}$, due to $\left(\partial^{2} \Pi_{i} / \partial p_{s}^{2}\right)=-2 k^{2}<0$, making $\left(\partial \Pi_{i} / \partial p_{s}\right)=0$, we have

$$
p_{s}\left(p, p_{i}, s\right)=\frac{\beta_{1} p+\mu s+k^{2} p_{i}+k^{2} c_{s}-\theta a}{2 k^{2}} \text {. }
$$

Substituting (20) into $\Pi_{m}$, due to $\left(\partial^{2} \Pi_{m} / \partial w^{2}\right)=-\beta_{1}-\beta_{2}<0$, letting $\left(\partial \Pi_{m} / \partial w\right)=0$, we have

$$
w(p, e, s)=\frac{a-\left(\beta_{1}+\beta_{2}\right)\left(p-c_{m}\right)+(k-\mu) e+(\lambda-\mu) s}{\beta_{1}+\beta_{2}} .
$$

Similarly, substituting (20)-(22) into $\Pi_{r}$, since $\Pi_{r}\left(p, p_{i}, s\right)$ is not jointly negative for $p, p_{i}$, and $s$, but it is jointly negative for $p_{i}$ and $s$, and the Hessian matrix is as follows:

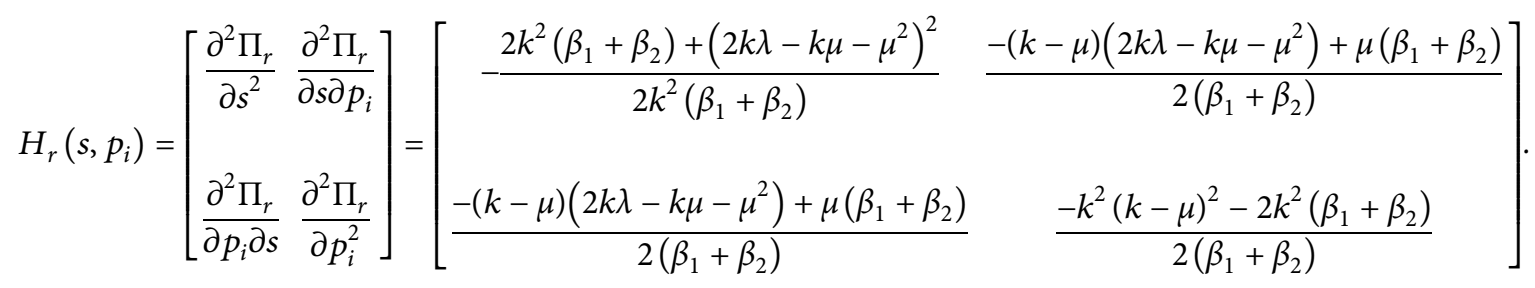

The above Hessian matrix satisfies the negative definite criterion, and it satisfies $\left(\left[2 k^{2}\left(\beta_{1}+\beta_{2}\right)+(2 k \lambda-k \mu-\right.\right.$ $\left.\left.\mu^{2}\right)^{2}\right]\left[(k-\mu)^{2}+2\left(\beta_{1}+\beta_{2}\right)\right]-\left[\mu\left(\beta_{1}+\beta_{2}\right)-(k-\mu)(2 k \lambda-\right.$ $\left.\left.\left.k \mu-\mu^{2}\right)\right]^{2}\right)>0$. Therefore, the optimal solution of the above three variables cannot be obtained directly from the first derivative. Based on the research design of Dan et al. [38], the two-stage optimization method can be used to obtain the optimal solution for this problem.

Stage 1. Taking the first-order partial derivatives of $\Pi_{r}$ with respect to $s$ and $p_{i}$, the following equation can be obtained:

$s\left(p, p_{i}\right)=\frac{\left(\left(2 k \beta_{1}+3 k \beta_{2}+\mu \beta_{1}\right)\left(2 k \lambda-k \mu-\mu^{2}\right) p-\left[-k^{2} \mu\left(\beta_{1}+\beta_{2}\right)+k^{2}(k-\mu)\left(2 k \lambda-k \mu-\mu^{2}\right)\right] p_{i}+\left[-2 k a+(k-\mu)\left(k^{2} c_{s}+\theta a\right)-k\left(\beta_{1}+\beta_{2}\right) c_{m}\right]\left(2 k \lambda-k \mu-\mu^{2}\right)\right)}{2 k^{2}\left(\beta_{1}+\beta_{2}\right)+\left(2 k \lambda-k \mu-\mu^{2}\right)^{2}}$,

$p_{i}(p, s)=\frac{\left(\left[(k-\mu)\left(2 k \beta_{1}+3 k \beta_{2}+\mu \beta_{1}\right)+\beta_{1}\left(\beta_{1}+\beta_{2}\right)\right] p t+n\left[\left(\beta_{1}+\beta_{2}\right) \mu-(k-\mu)\left(2 k \lambda-k \mu-\mu^{2}\right)\right] q s h-\left(\left(\theta a-k^{2} c_{s}\right)\left(\beta_{1}+\beta_{2}\right)-(k-\mu)\left[(k-\mu)\left(\theta a+k^{2} c_{s}\right)-k\left(\beta_{1}+\beta_{2}\right) c_{m}-2 k a\right]\right)\right)}{k^{2}\left[(k-\mu)^{2}+2\left(\beta_{1}+\beta_{2}\right)\right]}$ 
Solving (24) and (25) simultaneously, we can derive that

$$
\begin{aligned}
&\left(2 k^{2}\left(\beta_{1}+\beta_{2}\right)\left[(k-\mu)\left(2 k \beta_{1}+3 k \beta_{2}+\mu \beta_{1}\right)+\beta_{1}\left(\beta_{1}+\beta_{2}\right)\right]\right. \\
&\left.+\left(2 k \lambda-k \mu-\mu^{2}\right)\left(\beta_{1}+\beta_{2}\right)\left[\left(2 k \beta_{1}+3 k \beta_{2}+\mu \beta_{1}\right) \mu+\left(2 k \lambda-k \mu-\mu^{2}\right) \beta_{1}\right]\right) p \\
&+\left[-2 k a+(k-\mu)\left(k^{2} c_{s}+\theta a\right)-k\left(\beta_{1}+\beta_{2}\right) c_{m}\right]\left(2 k \lambda-k \mu-\mu^{2}\right)\left[\left(\beta_{1}+\beta_{2}\right) \mu-(k-\mu)\left(2 k \lambda-k \mu-\mu^{2}\right)\right] \\
&\left.\left.-\left[2 k^{2}\left(\beta_{1}+\beta_{2}\right)+\left(2 k \lambda-k \mu-\mu^{2}\right)^{2}\right]\left(\left(\theta a-k^{2} c_{s}\right)\left(\beta_{1}+\beta_{2}\right)-(k-\mu)\left[(k-\mu)\left(\theta a+k^{2} c_{s}\right)-k\left(\beta_{1}+\beta_{2}\right) c_{m}-2 k a\right]\right)\right)\right) \\
& p_{i}(p)=\frac{k^{2}\left[2 k^{2}\left(\beta_{1}+\beta_{2}\right)+\left(2 k \lambda-k \mu-\mu^{2}\right)^{2}\right]\left[(k-\mu)+2\left(\beta_{1}+\beta_{2}\right)\right]-k^{2}\left[\mu\left(\beta_{1}+\beta_{2}\right)-(k-\mu)\left(2 k \lambda-k \mu-\mu^{2}\right)\right]^{2}}{(26)} \\
&+\left(2\left(\beta_{1}+\beta_{2}\right) k^{2}\left[\left(2 k \beta_{1}+3 k \beta_{2}+\mu \beta_{1}\right)+\left(2 k \lambda-k \mu-\mu^{2}\right)\right]+k^{2} \mu\left(\beta_{1}+\beta_{2}\right)\left[(k-\mu)\left(2 k \beta_{1}+3 k \beta_{2}+\mu \beta_{1}\right)+\beta_{1}\left(\beta_{1}+\beta_{2}\right)\right]\right. \\
&\left.-k^{2}(k-\mu)\left(2 k \lambda-k \mu-\mu^{2}\right) \beta_{1}\left(\beta_{1}+\beta_{2}\right)\right) p \\
&+k^{2} \mu\left(\beta_{1}+\beta_{2}\right)\left(2\left(\beta_{1}+\beta_{2}\right) k^{2}\left[\left(2 k \beta_{1}+3 k \beta_{2}+\mu \beta_{1}\right)+\left(2 k \lambda-k \mu-\mu^{2}\right)\right]\right. \\
&\left.+k^{2} \mu\left(\beta_{1}+\beta_{2}\right)\left[(k-\mu)\left(2 k \beta_{1}+3 k \beta_{2}+\mu \beta_{1}\right)+\beta_{1}\left(\beta_{1}+\beta_{2}\right)\right]-k^{2}(k-\mu)\left(2 k \lambda-k \mu-\mu^{2}\right) \beta_{1}\left(\beta_{1}+\beta_{2}\right)\right) \\
&+\left(\left(k^{2} c_{s}+\theta a\right)\left(\beta_{1}+\beta_{2}\right)-(k-\mu)\left[(k-\mu)\left(k^{2} c_{s}+\theta a\right)-\left(\beta_{1}+\beta_{2}\right) c_{m}-2 k a\right]\right) \\
&\left.+k^{2}(k-\mu)\left(2 k \lambda-k \mu-\mu^{2}\right)\left(k^{2} c_{s}+\theta a\right)\left(\beta_{1}+\beta_{2}\right)+2\left(\beta_{1}+\beta_{2}\right) k^{2}\left[-2 k a+(k-\mu)\left(\theta a+k^{2} c_{s}\right)\left(\beta_{1}+\beta_{2}\right)-k\left(\beta_{1}+\beta_{2}\right) c_{m}\right]\left(2 k \lambda-k \mu-\mu^{2}\right)\right) \\
&\left(k^{2}\left[2 k^{2}\left(\beta_{1}+\beta_{2}\right)+\left(2 k \lambda-k \mu-\mu^{2}\right)^{2}\right]\left[(k-\mu)^{2}+2\left(\beta_{1}+\beta_{2}\right)\right]-k^{2}\left[\mu\left(\beta_{1}+\beta_{2}\right)-(k-\mu)\left(2 k \lambda-k \mu-\mu^{2}\right)\right]^{2}\right)
\end{aligned}
$$

Stage 2. Substitute (26) and (27) into $\Pi_{r}\left(p, p_{i}, s\right)$, respectively, making its first derivative to $p$ be 0 . Since $\left(\partial^{2} \Pi_{r} / \partial p^{2}\right)<0$, the optimal product retail price $p^{d *}$ is as follows:

$$
p^{d *}=\frac{\left(\xi_{1} \xi_{5}+\xi_{3} \xi_{7}\right)\left(\xi_{2} \xi_{4}+\xi_{1} \xi_{11}\right)+\left(\xi_{1} \xi_{10}-\xi_{2} \xi_{3}\right)\left(\xi_{7} \xi_{4}-\xi_{1} \xi_{8}\right)}{\left(\xi_{1} \xi_{9}-\xi_{2}^{2}\right)\left(\xi_{1} \xi_{5}+\xi_{3} \xi_{7}\right)-\left(\xi_{1} \xi_{10}-\xi_{2} \xi_{3}\right)\left(\xi_{1} \xi_{6}+\xi_{2} \xi_{7}\right)}
$$

Substituting (28) into (26) and (27), the optimal logistics service sale price $p_{i}^{d *}$ and offline comprehensive experience service level $s^{d *}$ are as follows:

$$
\begin{aligned}
p_{i}^{d *} & =\frac{\left(\xi_{1} \xi_{6}+\xi_{2} \xi_{7}\right) p^{d *}+\xi_{7} \xi_{4}-\xi_{1} \xi_{8}}{\xi_{1} \xi_{5}+\xi_{3} \xi_{7}}, \\
s^{d *} & =\frac{\left(\xi_{2} \xi_{5}-\xi_{3} \xi_{6}\right) p^{d *}+\xi_{3} \xi_{8}+\xi_{4} \xi_{5}}{\xi_{1} \xi_{5}+\xi_{3} \xi_{7}} .
\end{aligned}
$$

Substituting (28)-(30) into (21)-(22), the optimal logistics service order price $p_{s}^{d *}$ and product wholesale price $w^{d *}$ are as follows:

$$
\begin{aligned}
& p_{s}^{d *}=\frac{\beta_{1} p^{d *}+\mu s^{d *}+k^{2} p_{i}^{d *}+k^{2} c_{s}-\theta a}{2 k^{2}}, \\
& w^{d *}=\frac{a-\left(\beta_{1}+\beta_{2}\right)\left(p^{d *}-c_{m}\right)+(k-\mu) e^{d *}+(\lambda-\mu) s^{d *}}{\beta_{1}+\beta_{2}} .
\end{aligned}
$$

Substituting (31) into (20), the optimal logistics service level $e^{d *}$ is as follows:

$$
e^{d *}=k\left(p_{s}^{d *}-c_{s}\right)
$$

Similarly, by substituting all the above optimal solutions into the demand functions of the online and offline channel, the profit function of each decision maker, and the total profit function of the supply chain, the expressions of the optimal functions are as follows:

$$
\begin{aligned}
& d_{o}^{d *}=\theta a-\beta_{1} p^{d *}+k e^{d *}-\mu s^{d *}, \\
& d_{f}^{d *}=(1-\theta) a-\beta_{2} p^{d *}+\lambda s^{d *}-\mu e^{d *} \\
& d^{d *}=d_{o}^{d *}+d_{f}^{d *}, \\
& \Pi_{r}^{d *}=d^{d *}\left(p^{d *}-w^{d *}\right)-d_{o}^{d *} p_{i}^{d *}-\frac{1}{2}\left(s^{d *}\right)^{2}, \\
& \Pi_{m}^{d *}=d^{d *}\left(w^{d *}-c_{m}\right), \\
& \Pi_{i}^{d *}=d_{o}^{d *}\left(p_{i}^{d *}-p_{s}^{d *}\right), \\
& \Pi_{s}^{d *}=d_{o}^{d *}\left(p_{s}^{d *}-c_{s}\right)-\frac{1}{2}\left(e^{d *}\right)^{2} \\
& \Pi^{d *}=\Pi_{r}^{d *}+\Pi_{m}^{d *}+\Pi_{i}^{d *}+\Pi_{s}^{d *} .
\end{aligned}
$$

Among them, $\xi_{1}=2 k^{2}\left(\beta_{1}+\beta_{2}\right)+\left(2 k \lambda-k \mu-\mu^{2}\right)^{2}$, $\xi_{2}=\left(2 k \beta_{1}+3 k \beta_{2}+\mu \beta_{1}\right)\left(2 k \lambda-k \mu-\mu^{2}\right)$, 


$$
\begin{aligned}
& \xi_{3}=-k^{2} \mu\left(\beta_{1}+\beta_{2}\right)+k^{2}(k-\mu)\left(2 k \lambda-k \mu-\mu^{2}\right) \\
& \xi_{4}=\left[-2 k a+(k-\mu)\left(k^{2} c_{s}+\theta a\right)-k\left(\beta_{1}+\beta_{2}\right) c_{m}\right]\left(2 k \lambda-k \mu-\mu^{2}\right) \\
& \xi_{5}=k^{2}\left[(k-\mu)^{2}+2\left(\beta_{1}+\beta_{2}\right)\right] \\
& \xi_{6}=(k-\mu)\left(2 k \beta_{1}+3 k \beta_{2}+\mu \beta_{1}\right)+\beta_{1}\left(\beta_{1}+\beta_{2}\right) \\
& \xi_{7}=\left(\beta_{1}+\beta_{2}\right) \mu-(k-\mu)\left(2 k \lambda-k \mu-\mu^{2}\right) \\
& \xi_{8}=\left(\theta a-k^{2} c_{s}\right)\left(\beta_{1}+\beta_{2}\right)-(k-\mu)\left[(k-\mu)\left(\theta a+k^{2} c_{s}\right)-k\left(\beta_{1}+\beta_{2}\right) c_{m}-2 k a\right] \\
& \xi_{9}=\left(2 k \beta_{2}+k \beta_{1}+\mu \beta_{1}\right)\left[4 k\left(\beta_{1}+\beta_{2}\right)-\beta_{1}(k-\mu)\right] \\
& \xi_{10}=k^{2}(k-\mu)\left(2 k \beta_{1}+3 k \beta_{2}+\mu \beta_{1}\right)+k^{2}\left(\beta_{1}+\beta_{2}\right) \beta_{1}, \\
& \xi_{11}=\left[2 k a-(k-\mu)\left(k^{2} c_{s}+\theta a\right)\right]\left(2 k \beta_{1}+3 k \beta_{2}+\mu \beta_{1}\right)-k\left(\beta_{1}+\beta_{2}\right) c_{m}\left(-k \beta_{1}-\mu \beta_{1}-2 k \beta_{2}\right) .
\end{aligned}
$$

Proposition 9. In the decentralized decision-making mode, the retail price $p$ increases with the sale price $p_{i}$ of logistics service and the offline comprehensive experience service level $s$; the order price $p_{s}$ of logistics service increases with logistics service level $e$.

Proof.

$\frac{\mathrm{d} p^{d *}}{\mathrm{~d} p_{i}}=\frac{\left(k^{2}\left[2 k^{2}\left(\beta_{1}+\beta_{2}\right)+\left(2 k \lambda-k \mu-\mu^{2}\right)^{2}\right]\left[(k-\mu)^{2}+2\left(\beta_{1}+\beta_{2}\right)\right]-k^{2}\left[\mu\left(\beta_{1}+\beta_{2}\right)-(k-\mu)\left(2 k \lambda-k \mu-\mu^{2}\right)\right]^{2}\right)}{\left(2 k^{2}\left(\beta_{1}+\beta_{2}\right)\left[(k-\mu)\left(2 k \beta_{1}+3 k \beta_{2}+\mu \beta_{1}\right)+\beta_{1}\left(\beta_{1}+\beta_{2}\right)\right]+\left(\beta_{1}+\beta_{2}\right)\left(2 k \lambda-k \mu-\mu^{2}\right)\left[\mu\left(2 k \beta_{1}+3 k \beta_{2}+\mu \beta_{1}\right)+\beta_{1}\left(2 k \lambda-k \mu-\mu^{2}\right)\right]\right)}$,

it can be shown that the numerator and denominator of this equation are greater than 0 , so $\left(\mathrm{d} p^{d *} / \mathrm{d} p_{i}\right)>0$. It can be seen that the retail price increases with the increase of logistics service sale price $p^{i}$.

Since

$\frac{\mathrm{d} p^{d *}}{\mathrm{~d} s}=\frac{\left(k^{2}\left[2 k^{2}\left(\beta_{1}+\beta_{2}\right)+\left(2 k \lambda-k \mu-\mu^{2}\right)^{2}\right]\left[(k-\mu)^{2}+2\left(\beta_{1}+\beta_{2}\right)\right]-k^{2}\left[\mu\left(\beta_{1}+\beta_{2}\right)-(k-\mu)\left(2 k \lambda-k \mu-\mu^{2}\right)\right]^{2}\right)}{\left(2 k^{2}\left(\beta_{1}+\beta_{2}\right)\left[\left(2 k \beta_{1}+3 k \beta_{2}+\mu \beta_{1}\right)\left(2 k \lambda-k \mu-\mu^{2}\right)\right]+k^{2} \mu\left(\beta_{1}+\beta_{2}\right)\left[(k-\mu)\left(2 k \beta_{1}+3 k \beta_{2}+\mu \beta_{1}\right)+\beta_{1}\left(\beta_{1}+\beta_{2}\right)\right]-k^{2}(k-\mu)\left(2 k \lambda-k \mu-\mu^{2}\right) \beta_{1}\left(\beta_{1}+\beta_{2}\right)\right)}$,

it can be shown that the numerator and denominator of this equation are both greater than 0 , so $\left(\mathrm{d} p^{d *} / \mathrm{d} s\right)>0$, and it can be seen that $s$ is positively correlated with $p$, which indicates that the product retail price also increases with $s$.

Since $\left(\mathrm{d} p_{s}^{d *} / \mathrm{d} e\right)=(1 / k)>0$, it can be seen that $p_{s}$ is positively related to $e$, so, the order price $p_{s}$ of logistics service increases with logistics service level $e$.

Proposition 10. In the decentralized decision-making mode, the price elasticity of the offline comprehensive experience service level and the logistics service sale price are both greater than 1.

Proof. Under the decentralized decision-making mode, the price elasticity of the offline comprehensive experience service level is $\varepsilon_{\mathrm{sp}}=((\Delta s / s) /(\Delta p / p))=\left(\left(\xi_{2} \xi_{5}-\xi_{3} \xi_{6}\right) p /\right.$ $\left.\left(\left(\xi_{2} \xi_{5}-\xi_{3} \xi_{6}\right) p+\xi_{3} \xi_{8}+\xi_{4} \xi_{5}\right)\right)$, since $\xi_{3} \xi_{8}+\xi_{4} \xi_{5}<0$ and $\xi_{2} \xi_{5}-\xi_{3} \xi_{6}>0$, so $\varepsilon_{\text {sp }}=((\Delta s / s) /(\Delta p / p))>1$, whereas the price elasticity of the offline comprehensive experience service level in the centralized decision-making mode varies with $\lambda$; when $\lambda$ is larger, its value is greater than 1 . It shows that different decision-making modes have different effects on the price elasticity of service level. In comparison, the price elasticity of the offline comprehensive experience service level in the decentralized decision-making mode is greater. That is to say, in the decentralized decision-making mode, as the leader of supply chain, the retailer should optimize the level of offline comprehensive experience service to a greater extent on the basis of the increasing product retail price in order to improve its competitiveness.

Similarly, the price elasticity of logistics service sale price is $\varepsilon_{p_{i} p_{i}}=\left(\left(\Delta p_{i} / p_{i}\right) /(\Delta p / p)\right)=\left(\left(\xi_{1} \xi_{6}+\xi_{2} \xi{ }_{7}\right) p^{d *} /\left(\left(\xi_{1} \xi_{6}+\right.\right.\right.$ $\left.\left.\left.\xi_{2} \xi_{7}\right) p^{d *}+\xi_{4} \xi_{7}-\xi_{1} \xi_{8}\right)\right)$, since $\xi_{4} \xi_{7}-\xi_{1} \xi_{8}<0$ and $\xi_{1} \xi_{6}+\xi_{2} \xi_{7}>0$, and it can be proved that $\varepsilon_{p_{i} p}=\left(\left(\Delta p_{i} / p_{i}\right) /\right.$ $(\Delta p / p))>1$. In other words, when the retail price of products increases, the retailer also needs to increase the 


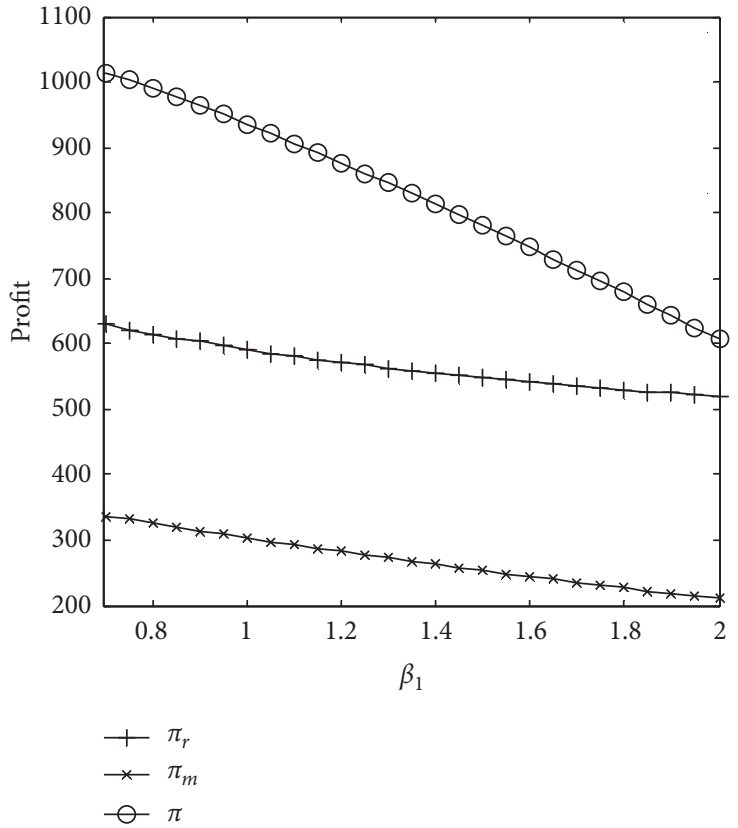

(a)

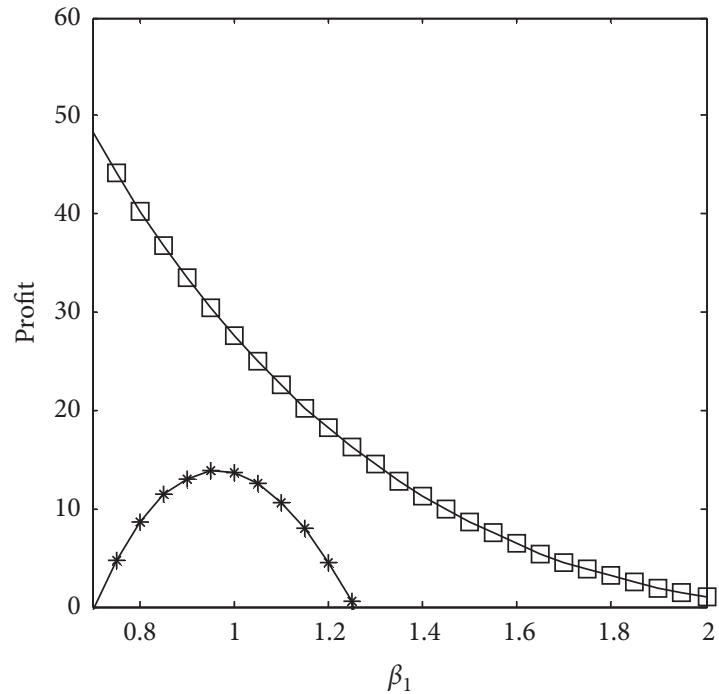

$\square \pi_{i}$

$\rightarrow \pi_{s}$

Figure 2: Variation tendency of $\Pi_{r}^{d *}, \Pi_{m}^{d *}, \Pi_{i}^{d *}, \Pi_{s}^{d *}$, and $\Pi^{d *}$ with $\beta_{1}$.

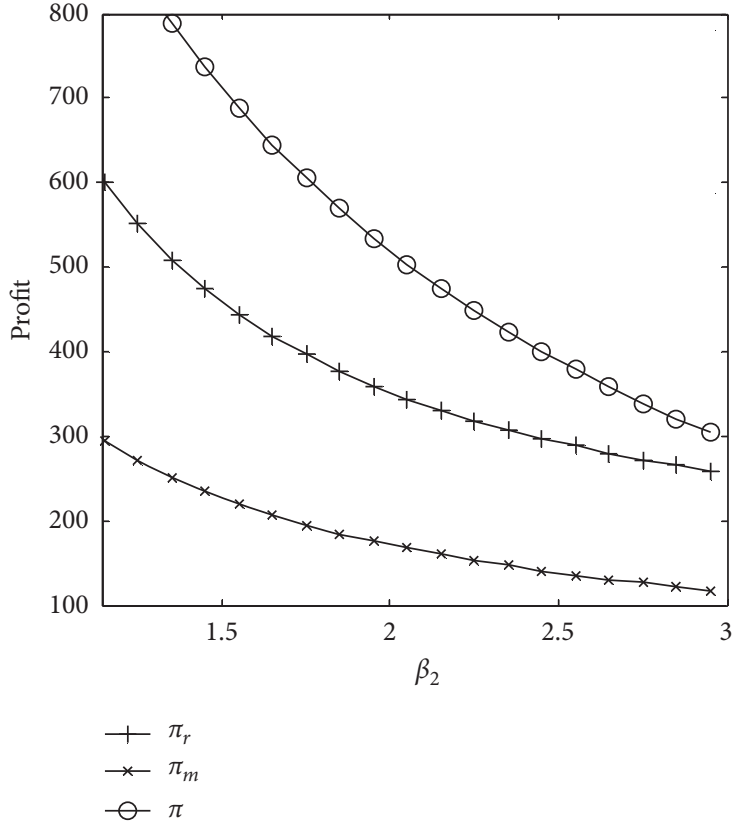

(a)

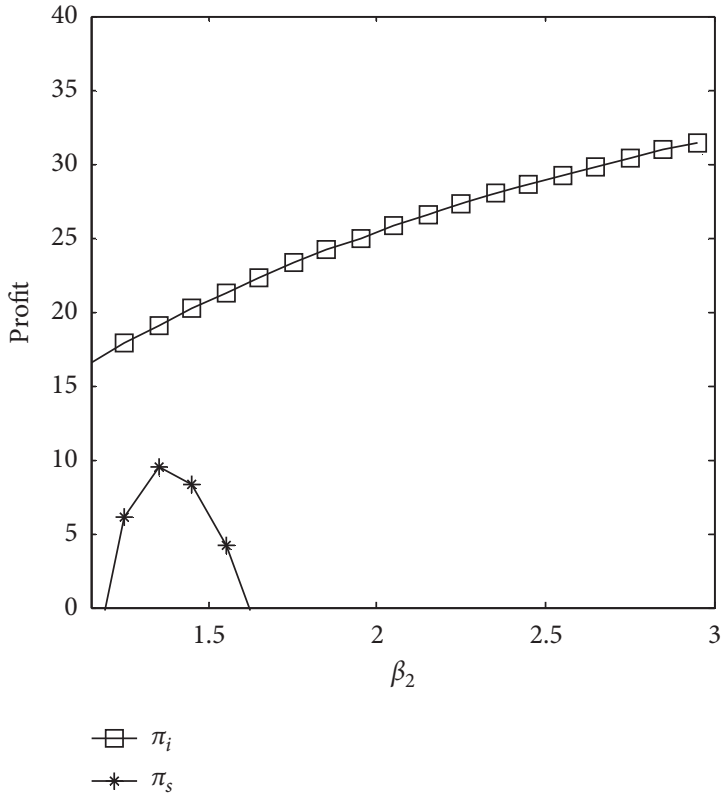

(b)

Figure 3: Variation tendency of $\Pi_{r}^{d *}, \Pi_{m}^{d *}, \Pi_{i}^{d *}, \Pi_{s}^{d *}$, and $\Pi^{d *}$ with $\beta_{2}$.

payment to LSI, so as to improve the logistics service level and enhance its competitive advantage in the whole supply chain system.

4.2.2. Numerical Analysis. Since the optimal decision in the decentralized decision-making mode and the analytic formula of the optimal profit function of each decision maker contain multiple parameters, the form is too complex to be directly analyzed by the analytical formula. Therefore, following Gao et al. [39], Li et al. [40], and Brojeswar et al. [41], the optimal decisions and the relationship between the optimal decisions of each decision maker will be explored by means of numerical simulation analysis. The initial assignment of the relevant parameters are as follows: $a=100$, 
$o=0.44, \beta_{1}=1.22, \beta_{2}=1.21, k=1.5, \mu=0.25, \lambda=0.88$, $c_{m}=0.05$, and $c_{s}=0.02$. The relationship between the parameters conforms to the above research hypothesis.

Through numerical simulation analysis and calculation, it can be derived that, under the decentralized decisionmaking mode, product retail price, wholesale price, logistics service level, offline comprehensive experience service level, profit function of each decision maker, and the total profit function of supply chain affected by the price sensitivity coefficient, service level sensitivity coefficient, and other relevant parameters are as follows:

(1) In the decentralized decision-making mode, the profits of the manufacturer, retailer, and whole supply chain all decrease with the increase of $\beta_{1}$ and $\beta_{2}$; the profit of LSI decreases with the increase of $\beta_{1}$ and increases with the increase of $\beta_{2}$; when $\beta_{2}<\beta_{1}$, the profit of FLSP decreases with the increase of $\beta_{1}$ and increases with the increase of $\beta_{2}$; when $\beta_{2}>\beta_{1}$, the profit of FLSP increases and then decreases with $\beta_{1}$ and $\beta_{2}$.

Figure 2 simulates the effect of $\beta_{1}$ on the profits of each decision maker and the whole supply chain in the decentralized decision-making mode. The simulation results show that the profits of each decision maker and the whole supply chain decrease with the increase of online retail price sensitivity coefficient $\beta_{1}$ except for FLSP.

The profits of each decision maker changing with $\beta_{2}$ are shown in Figure 3. The profits of the manufacturer, retailer, and total supply chain decrease with the increase of $\beta_{2}$, while the profit of LSI increases with the increase of $\beta_{2}$.

If $\beta_{1}<\beta_{2}=1.21$, then the profit of FLSP increases first and then decreases with $\beta_{1}$, and when $\beta_{1}=0.96$, FLSP's profit is maximized; if $\beta_{1}$ continues to increase, its profit will gradually decreases. That is to say, due to $\beta_{1}<\beta_{2}$, although $\beta_{1}$ is gradually increasing, it still has comparative advantages, so the profit of FLSP will increase with the increase of $\beta_{1}$. However, when $\beta_{1}$ increases to a certain extent, its relative advantage is lost; then, the profit of FLSP will gradually decline. If $\beta_{1}>\beta_{2}=1.21$, then the profit of FLSP decreases with the increase of $\beta_{1}$. So, the change direction of FLSP's profit with $\beta_{1}$ is closely related to the relative size of $\beta_{1}$ and $\beta_{2}$.

If $\beta_{2}>\beta_{1}$, FLSP's profit is maximized when $\beta_{2}=1.37$ and then decreases with the increase of $\beta_{2}$. If $\beta_{2}<\beta_{1}$, FLSP's profit increases with $\beta_{2}$. In other words, when consumers are more sensitive to offline product price, it is more conducive to increase online sales, thus improving the profits of FLSP and LSI.

By comparing Figures 2 and 3, it can be obtained that the retailer's profit and the total profit of the whole supply chain system are more elastic to $\beta_{2}$ than to $\beta_{1}$. In other words, compared with the change of $\beta_{1}$, the same proportion change of price sensitivity coefficient $\beta_{2}$ of the offline channel will make the profits of the retailer and whole supply chain system decline greatly.
In summary, whether $\beta_{1}$ or $\beta_{2}$ increases, consumers are more sensitive to the product retail price, and the profits of the retailer, manufacturer, and whole supply chain will decrease. When $\beta_{1}$ increases, the market demand of LSSC decreases and the profit of LSI decreases. On the contrary, when $\beta_{2}$ increases, the market demand of LSSC increases, so the profit of LSI increases. However, the relative size of $\beta_{1}$ and $\beta_{2}$ will affect the profit of FLSP in different degrees. When $\beta_{2}<\beta_{1}$, the profit of FLSP decreases with the increase of $\beta_{1}$ and it increases with the increase of $\beta_{2}$; when $\beta_{2}>\beta_{1}$, the profit of FLSP increases first and then decreases with the increase of $\beta_{1}$ and $\beta_{2}$. That is to say, the relative size of the price sensitivity coefficient of the online and offline channels will have an inconsistent impact on the profit of FLSP.

(2) In the decentralized decision-making mode, the wholesale price, retail price, and offline comprehensive experience service level all decrease with the increase of $\beta_{1}$ and $\beta_{2}$; while the logistics service level and logistics service price all increase with the increase of $\beta_{1}$ and decrease with the increase of $\beta_{2}$.

Figures 4 and 5 simulate the optimal price and service level decisions affected by $\beta_{1}$ and $\beta_{2}$ in the decentralized decision-making mode.

When $\beta_{1}$ and $\beta_{2}$ increase, it means that consumers are more sensitive to the product retail price of the online and offline channel. At this time, the online and offline demand of the whole supply chain decreases, and the corresponding product retail price, wholesale price, and offline comprehensive experience service level will decrease. When $\beta_{1}$ increases, it means that consumers are more sensitive to the price of the online channel, the product retail price, and the market demand of the online channel will decrease. In order to ensure the profit of LSI, the retailer will increase the sale price $p_{i}$ of logistics service so as to improve the logistics service level of the whole supply chain.

When $\beta_{2}$ increases, it means that consumers are more sensitive to the price of the offline channel and the online demand will increase. In order to improve its own profit, the retailer will reduce the logistics service price, which will result in a lower logistics service level. At this time, the retailer will gradually reduce the offline comprehensive experience service level so as to ensure its own profit. The above analysis shows that the level of logistics service and offline comprehensive experience service are influenced not only by the price sensitivity coefficient of its own channel but also by the price sensitivity coefficient of another channel, which is also reflected in logistics service price. Therefore, the decision makers in the supply chain system should pay close attention to the price sensitivity coefficient of different channels in order to maximize their own profits. 


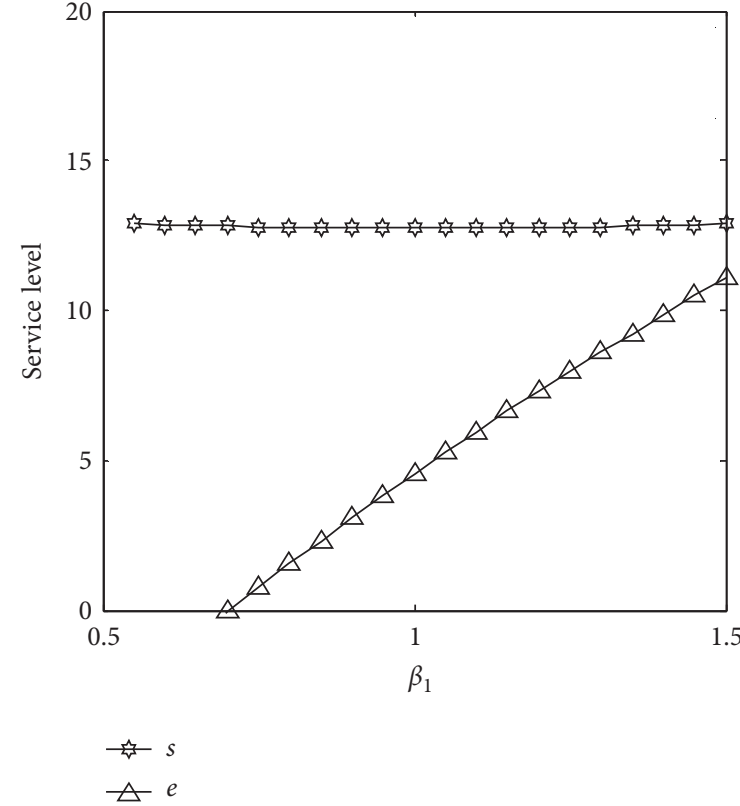

(a)

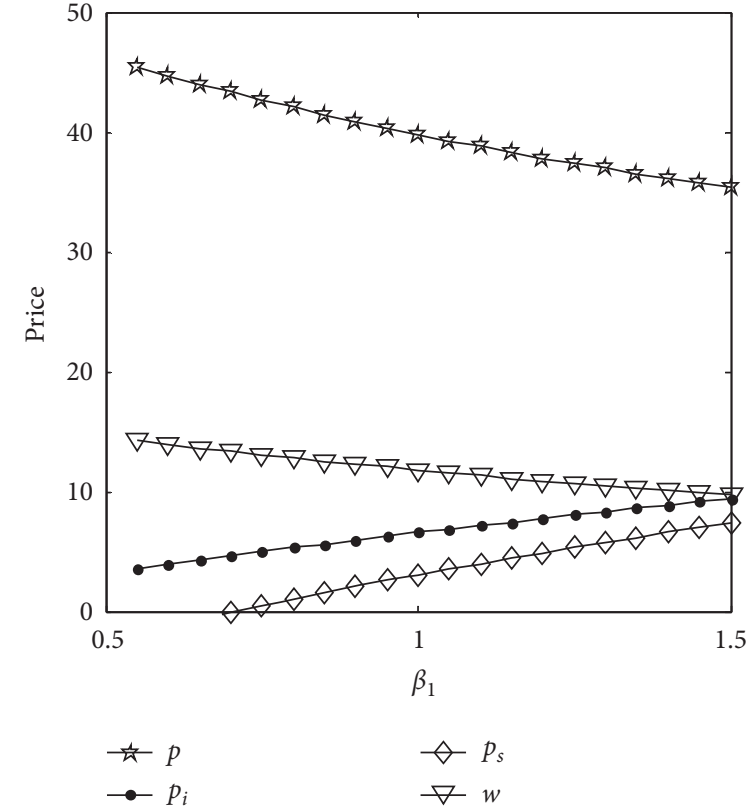

(b)

Figure 4: Variation tendency of $e^{d *}, s^{d *}, p^{d *}, w^{d *}, p_{i}^{d *}$, and $p_{s}^{d *}$ with $\beta_{1}$.

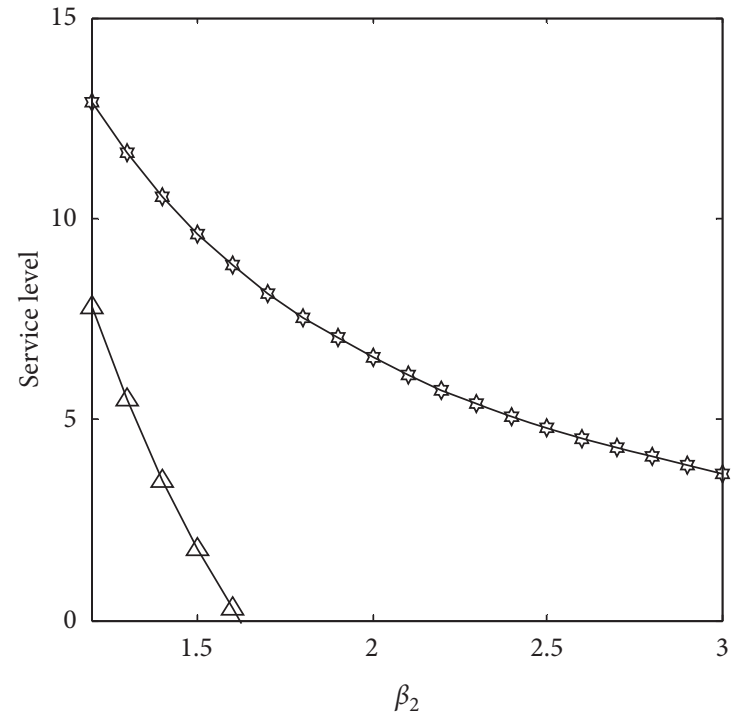

$\checkmark s$

$\triangle e$

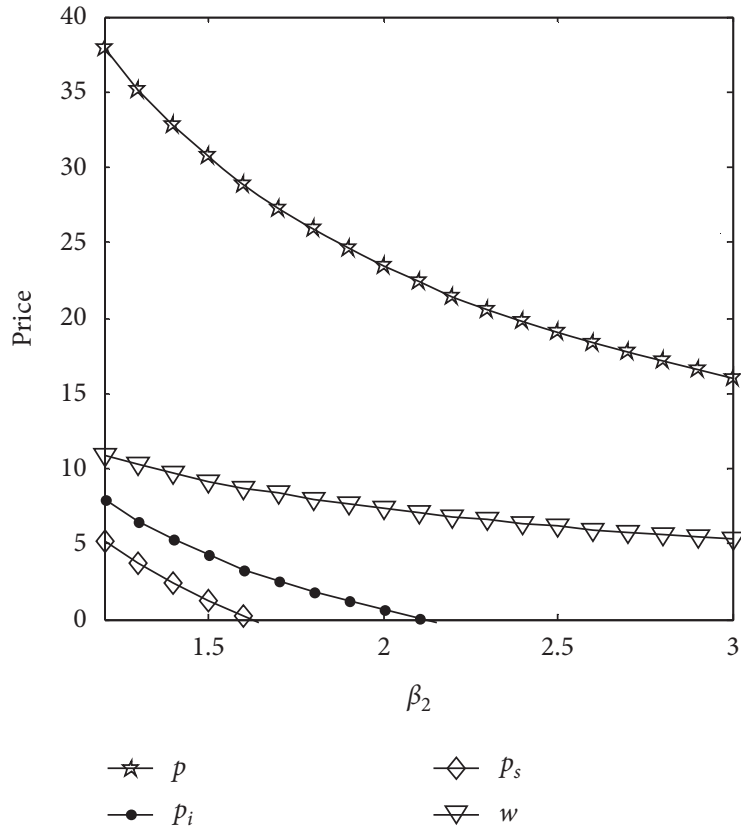

(b)

(a)

FIgURE 5: Variation tendency of $e^{d *}, s^{d *}, p^{d *}, w^{d *}, p_{i}^{d *}$, and $p_{s}^{d *}$ with $\beta_{2}$.

(3) In the decentralized decision-making mode, the optimal prices of the product and service and the optimal service level of the entire supply chain all decrease with $\mu$.

Figure 6 simulates the effects of $\mu$ on the optimal prices and service level under the decentralized decision-making mode. The data in the figure shows that the service level as well as product and service prices of the entire supply chain decrease with $\mu$. This finding is consistent with the centralized decisionmaking mode. In other words, the more intense the competition between online and offline channel, the lower the prices of the product and service and the service level. 


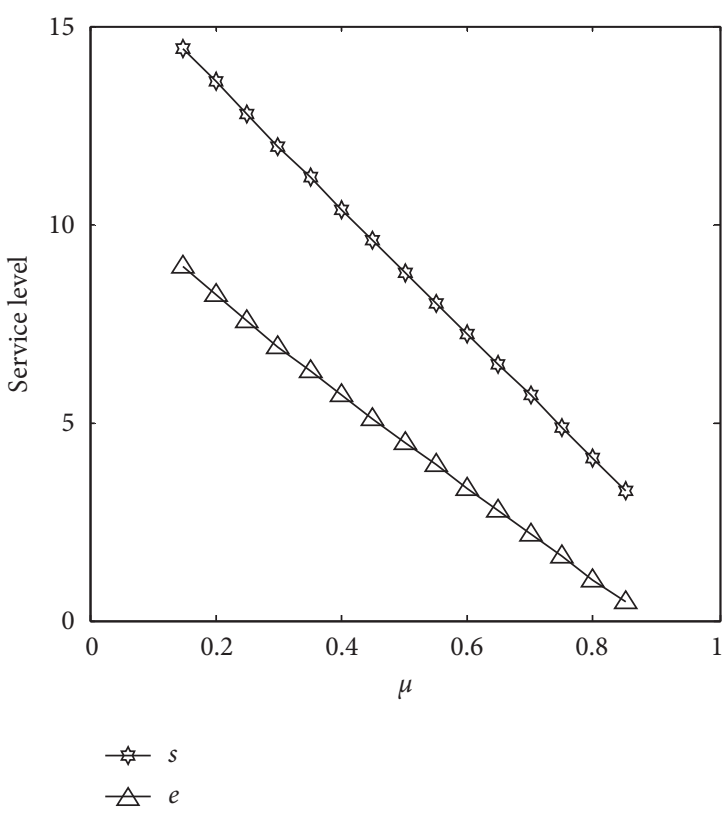

(a)

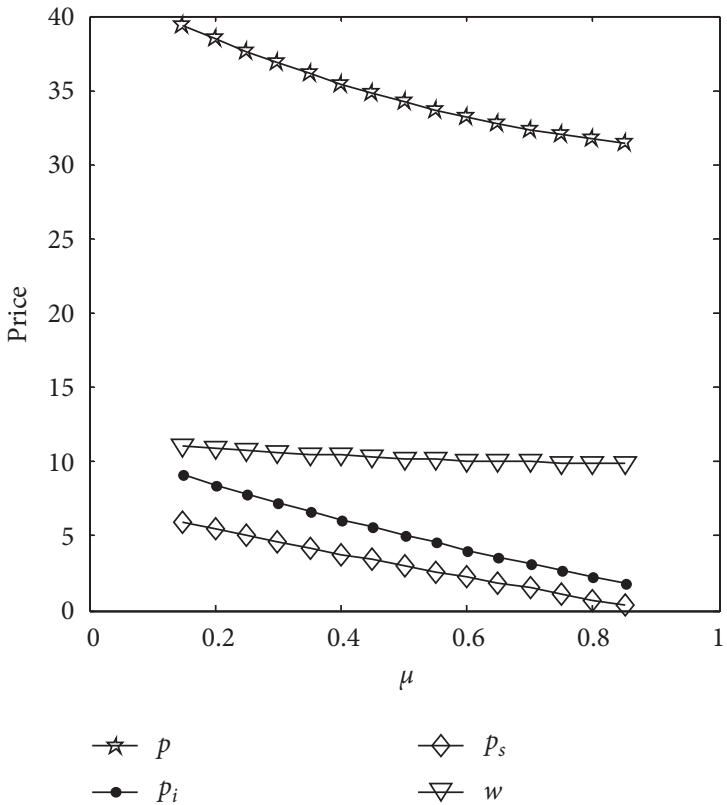

(b)

FIgURe 6: Variation tendency of $e^{d *}, s^{d *}, p^{d *}, w^{d *}, p_{i}^{d *}$, and $p_{s}^{d *}$ with $\mu$.

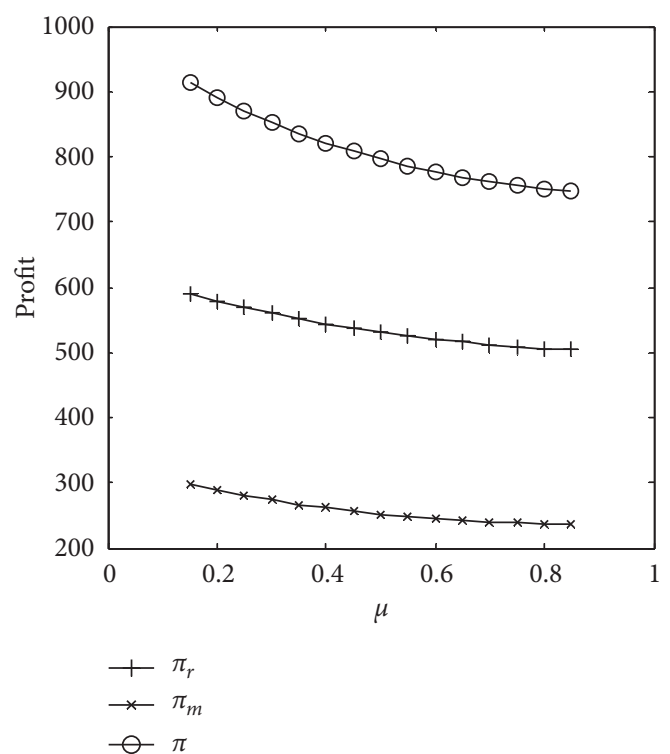

(a)

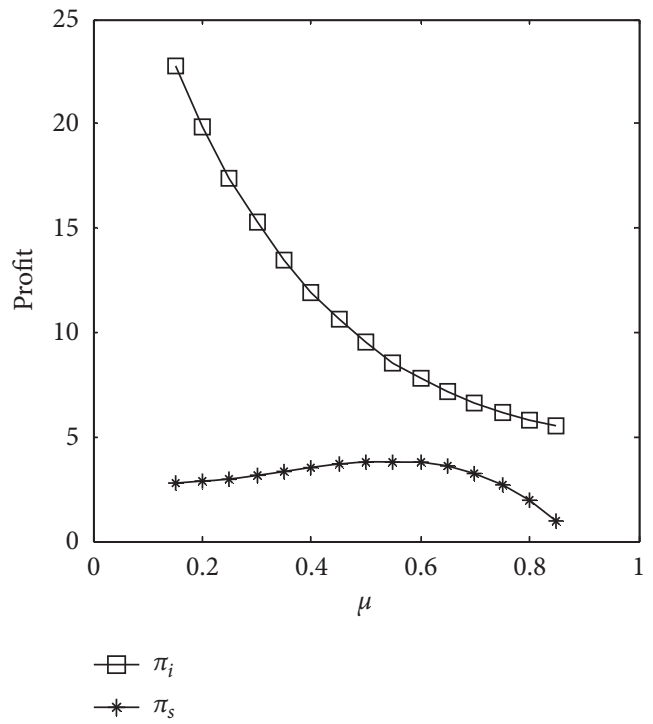

(b)

Figure 7: Variation tendency of $\Pi_{r}^{d *}, \Pi_{m}^{d *}, \Pi_{i}^{d *}, \Pi_{s}^{d *}$, and $\Pi^{d *}$ with $\mu$.

The increase of $\mu$ makes the competition between online and offline channels more intense, which will cause the prices of the product and service to gradually drop. At the same time, the decline of the price is not conducive to the optimization of service level throughout the supply chain.

(4) In the decentralized decision-making mode, the profits of each decision maker in PSC decrease with $\mu$. The profit of LSI decreases with $\mu$. The profit of
FLSP increases first and then decreases with the increase of $\mu$.

Figure 7 simulates the effects of $\mu$ on the optimal profits of each decision maker in the decentralized decision-making mode. According to the numerical analysis results, except for FLSP, the profits of each decision maker in the supply chain decrease with the increase of $\mu$. The increase of $\mu$ represents the fierce competition between online and offline 


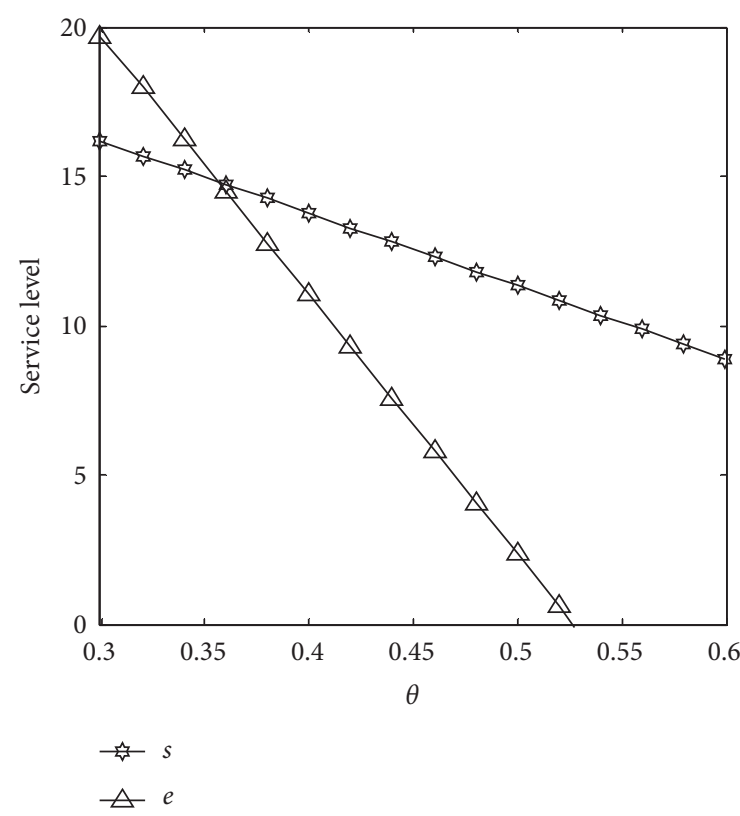

(a)

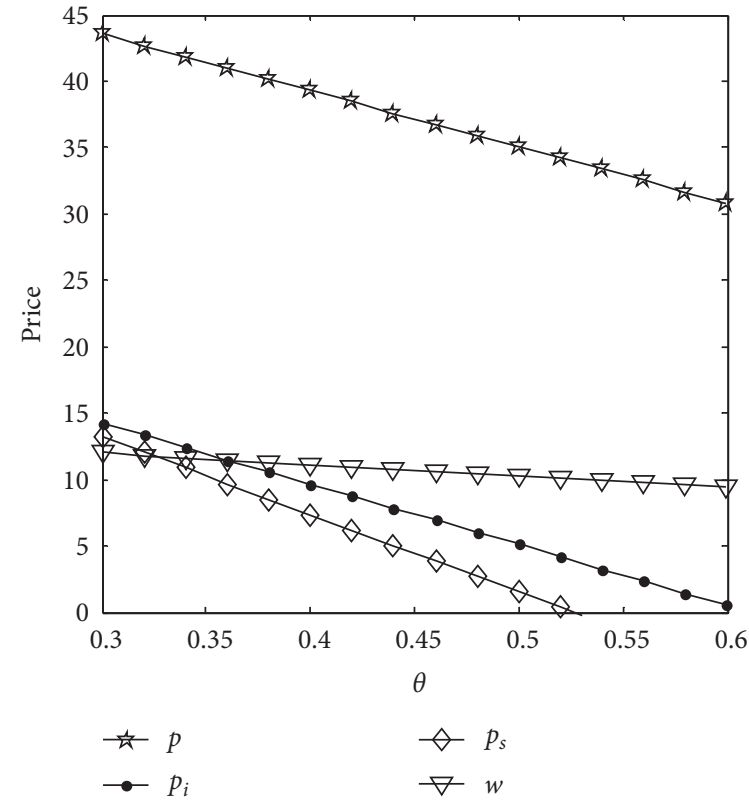

(b)

Figure 8: Variation tendency of $e^{d *}, s^{d *}, p^{d *}, w^{d *}, p_{i}^{d *}$, and $p_{s}^{d *}$ with $\theta$.

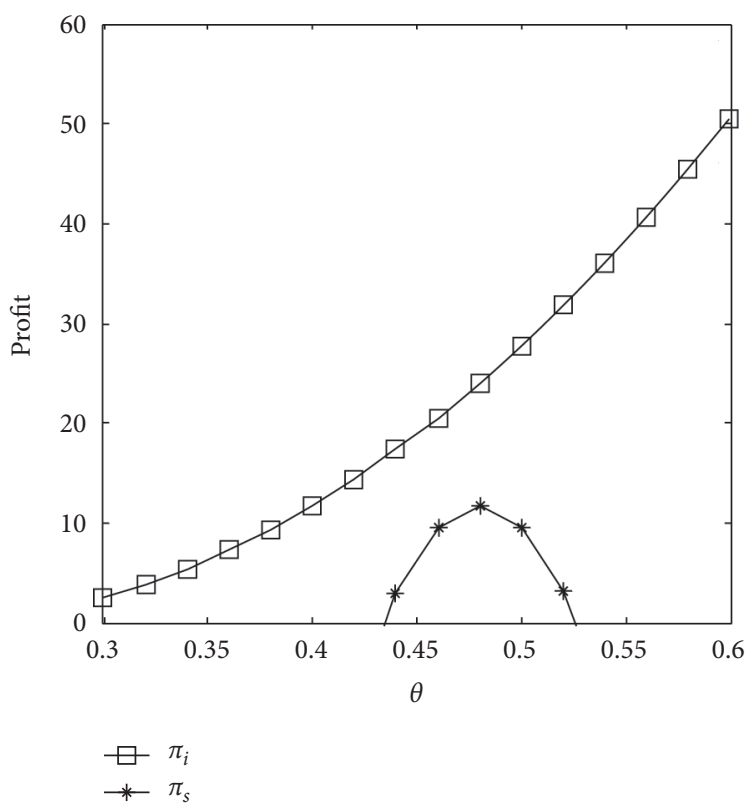

(a)

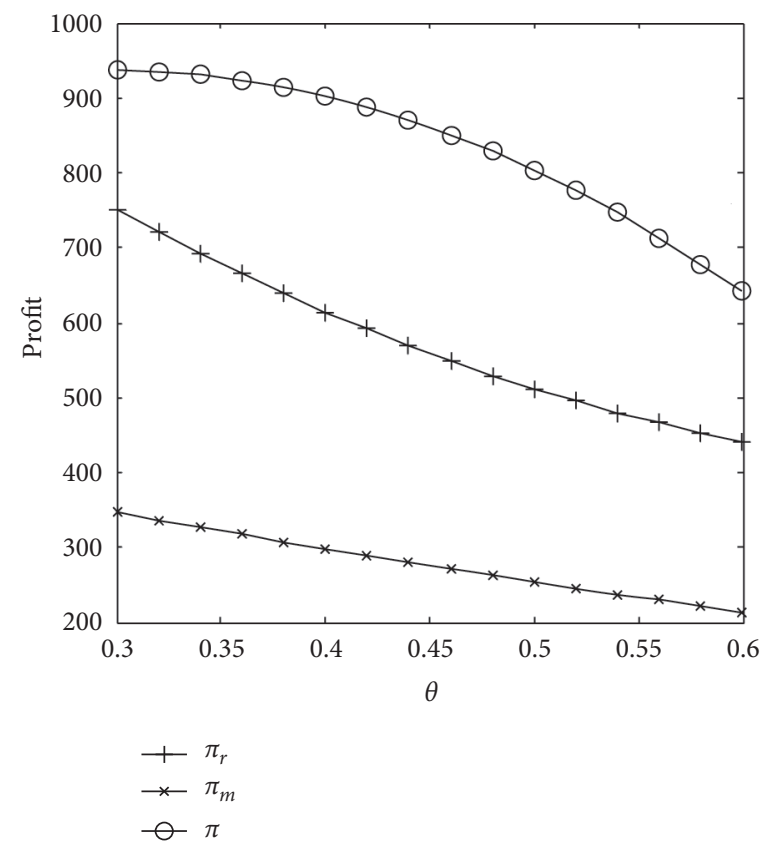

(b)

FIgURE 9: Variation tendency of $\Pi_{r}^{d *}, \Pi_{m}^{d *}, \Pi_{i}^{d *}, \Pi_{s}^{d *}$, and $\Pi^{d *}$ with $\theta$.

channels. At this time, the profits of the whole supply chain and all decision makers will decline. The profit of FLSP increases first and then decreases. When $\mu=0.55$, its profit is the largest and then decreases with the increase of $\mu$. Due to the fierce competition between online and offline, as the decision maker of logistics service in LSSC, it will first reduce the logistics service level. Combined with Figure 6, it can be concluded that the decline rate of the logistics service level is far greater than that of logistics service price. Therefore, the profit of FLSP will gradually increase in a short term, but it will gradually decline with the increase of $\mu$ in the later stage. 
(5) Under the decentralized decision-making mode, the service level of the whole supply chain system, the prices of product, and service all decrease with the increase of $\theta$; the profits of each decision maker of PSC decrease with the increase of $\theta$; the profit of LSI increases with the increase of $\theta$, and the profit of FLSP shows an increasing and then decreasing trend with the increase of $\theta$.

Figures 8 and 9 simulate the influence of $\theta$ on the optimal service level, the optimal prices, and the optimal profits of each decision maker in the decentralized decision-making mode.

The data in the figure implies that the optimal prices of the product and service and optimal service level decrease with the increase of $\theta$. This is because when consumers' loyalty to the online channel increases, the demand of the online channel increases. As all decision makers take their own profit maximization as the decision goal, FLSP and retailer will reduce their service level so as to ensure their own profits, which also makes the product prices and service prices decline. This conclusion is consistent with the research conclusion of Gao et al. [37].

The increase of market demand of the online channel will increase the profit of LSI, so the profit of LSI increases with the increasing of $\theta$. The profit of FLSP, however, increases first and then decreases; this is because as a follower of LSSC, when the demand of the online channel increases to a certain extent, more profits are obtained by LSI, the leader of LSSC, which leads to the gradual decrease of FLSP's profit.

In summary, the retailer's profit is the highest and FLSP's profit is the lowest in the decentralized decision-making mode. Moreover, the profit of FLSP fluctuates greatly with the changes of retail price sensitivity coefficient, cross-service level sensitivity coefficient, and customers' loyalty to online channel, so the interest of FLSP is difficult to be guaranteed.

\section{Improved Residual Profit-Sharing Coordination Mechanism}

Compared with the centralized decision-making mode, the total profit of the dual-channel supply chain under the decentralized decision-making mode is lower. And the profits of some participants are difficult to be guaranteed, which is not conducive to the long-term and stable development of the whole supply chain system.

5.1. Model Construction. The traditional residual profit sharing coordination mechanism mostly uses the profit contribution value to determine the profit sharing coefficient. Although this approach can achieve the interest coordination of the supply chain, it is more ideal and does not consider the bargaining power of each participant. The research object of this paper includes four decision makers, and the bargaining power of different decision makers is quite different. This paper designs an improved residual profit-sharing coordination mechanism that takes the bargaining power of each participant into account and makes the interest coordination contract more realistic. The model of an improved residual profit-sharing coordination mechanism is as follows:

$$
\begin{aligned}
& \max \Pi^{h}\left(p, p_{i}, p_{s}, e, s, w\right)=\left(\left[a-\left(\beta_{1}+\beta_{2}\right) p+(k-\mu) e+(\lambda-\mu) s\right]\left(p-c_{m}\right)-\left(\theta a-\beta_{1} p+k e-\mu s\right) c_{s}-\frac{1}{2} s^{2}-\frac{1}{2} e^{2}\right) \\
& \operatorname{s.t.}\left\{\begin{array}{l}
\Pi_{m}^{h d}=\left(d_{o}+d_{f}\right)\left(w-c_{m}\right) \geq \Pi_{m}^{d *}+a_{m} \Delta \Pi, \\
\Pi_{r}^{h d}=d_{o}\left(p-w-p_{i}\right)+d_{f}(p-w)-\frac{1}{2} s^{2} \geq \Pi_{r}^{d *}+a_{r} \Delta \Pi, \\
\Pi_{i}^{h d}=d_{o}\left(p_{i}-p_{s}\right) \geq \Pi_{i}^{d *}+a_{i} \Delta \Pi, \\
\Delta \Pi_{f}=d_{f}\left(p_{s}-c_{s}\right)-\frac{1}{2} e^{2} \geq \Pi_{s}^{d *}+a_{s} \Delta \Pi, \\
0 \leq a_{m}+a_{r}+a_{i}+a_{s} \leq 1 \\
p, p_{i}, p_{s}, e, s, w \geq 0
\end{array}\right.
\end{aligned}
$$

In the model, $a_{m}, a_{r}, a_{i}$, and $a_{s}$ are the bargaining power coefficients of the manufacturer, retailer, LSI, and FLSP, respectively, which reflect the bargaining power of each participant. $\Delta \Pi$ is the residual profit, which is the difference 
between the profit under the centralized decision-making mode and decentralized decision-making mode. On the premise that the bargaining power of each decision maker is known, the optimal decisions of each decision maker can be calculated when the total profit of supply chain is maximized.

Among them, the bargaining power coefficient can be measured by the Nash negotiation model and the minimum core method. The Nash negotiation model used to measure the bargaining power coefficient is as follows:

$$
\begin{aligned}
& \max Z=\left(\eta_{m} \Pi^{c *}-\Pi_{m}^{d *}\right)\left(\eta_{r} \Pi^{c *}-\Pi_{r}^{d *}\right)\left(\eta_{i} \Pi^{c *}-\Pi_{i}^{d *}\right)\left(\left(1-\eta_{m}-\eta_{r}-\eta_{i}\right) \Pi^{c *}-\Pi_{s}^{d *}\right) \\
& \text { s.t. }\left\{\begin{array}{l}
\Pi_{m}^{h d}=\eta_{m} \Pi^{c *} \geq \Pi_{m}^{d *} \\
\Pi_{r}^{h d}=\eta_{r} \Pi^{c *} \geq \Pi_{r}^{d *} \\
\Pi_{i}^{h d}=\eta_{i} \Pi^{c *} \geq \Pi_{i}^{d *} \\
\Pi_{s}^{h d}=\left(1-\eta_{m}-\eta_{r}-\eta_{i}\right) \Pi^{c *} \geq \Pi_{s}^{d *} \\
\Pi_{l}^{h d}=\left(1-\eta_{m}-\eta_{r}\right) \Pi^{c *} \geq \Pi_{l}^{c c *} \\
\Pi_{p}^{h d}=\left(\eta_{m}+\eta_{r}\right) \Pi^{c *} \geq \Pi_{p}^{c c *} \\
\Pi_{r l}^{h t}=\left(1-\eta_{m}\right) \Pi^{c *} \geq \Pi_{r l}^{t *} \\
0<\eta_{m}<1,0<\eta_{r}<1,0<\eta_{i}<1
\end{array}\right.
\end{aligned}
$$

In the Nash negotiation model, $\eta_{m}, \eta_{r}, \eta_{i}$, and $\eta_{s}=(1-$ $\left.\eta_{m}-\eta_{r}-\eta_{i}\right)$ represent the bargaining power coefficients of manufacturer, retailer, LSI, and FLSP, respectively. $\Pi_{l}^{c c *}$ and $\Pi_{p}^{c c *}$ are the profits of LSSC and PSC under the centralized decision mode of PSC/LSSC (manufacturer and retailer adopt centralized decision-making mode, LSI and FLSP also adopt centralized decision-making mode, and PSC and LSSC play games based on the price of logistics service), $\Pi_{r l}^{t *}$ is the sum of the profits of retailer, and LSSC under the cooperative decision-making mode of retailer and LSSC. The above profit functions can be solved, respectively, by the reverse induction method, which are omitted here.

The model for calculating the bargaining power coefficient through the minimum core method is as follows:

$$
\begin{aligned}
& \min \varepsilon \\
& \text { s.t. }\left\{\begin{array}{l}
\Pi_{m}^{h d}=\widetilde{\eta}_{m} \Pi^{c *} \geq \Pi_{m}^{d *}, \\
\Pi_{r}^{h d}=\widetilde{\eta}_{r} \Pi^{c *} \geq \Pi_{r}^{d *}, \\
\Pi_{i}^{h d}=\widetilde{\eta}_{i} \Pi^{c *} \geq \Pi_{i}^{d *}, \\
\Pi_{s}^{h d}=\left(1-\widetilde{\eta}_{m}-\widetilde{\eta}_{r}-\widetilde{\eta}_{i}\right) \Pi^{c *} \geq \Pi_{s}^{d *}, \\
\Pi_{l}^{h d}=\left(1-\widetilde{\eta}_{m}-\widetilde{\eta}_{r}\right) \Pi^{c *}+\varepsilon \geq \Pi_{l}^{c c *}, \\
\Pi_{p}^{h d}=\left(\widetilde{\eta}_{m}+\widetilde{\eta}_{r}\right) \Pi^{c *}+\varepsilon \geq \Pi_{p}^{c c *}, \\
\Pi_{r l}^{h t}=\left(1-\widetilde{\eta}_{m}\right) \Pi^{c *}+\varepsilon \geq \Pi_{r l}^{t *}, \\
0<\widetilde{\eta}_{m}<1,0<\widetilde{\eta}_{r}<1,0<\widetilde{\eta}_{i}<1 .
\end{array}\right.
\end{aligned}
$$

Among them, $\widetilde{\eta}_{m}, \widetilde{\eta}_{r}, \widetilde{\eta}_{i}$, and $\widetilde{\eta}_{s}=\left(1-\widetilde{\eta}_{m}-\widetilde{\eta}_{r}-\widetilde{\eta}_{i}\right)$ are the bargaining power coefficients of each decision maker calculated by the minimum core method, respectively.

By averaging the bargaining power coefficients from the Nash negotiation model and the minimum core method, the corrected bargaining power coefficients are as follows:

$$
\begin{gathered}
\bar{\eta}_{m}=\frac{\eta_{m}+\tilde{\eta}_{m}}{2}, \\
\bar{\eta}_{r}=\frac{\eta_{r}+\tilde{\eta}_{r}}{2}, \\
\bar{\eta}_{i}=\frac{\eta_{i}+\tilde{\eta}_{i}}{2}, \\
\bar{\eta}_{s}=\frac{\eta_{s}+\tilde{\eta}_{s}}{2} .
\end{gathered}
$$

In order to compare and analyze the rationality of the above three bargaining power coefficients and the fairness of profit distribution, the above three kinds of bargaining power coefficients will be, respectively, substituted into the residual profit-sharing coordination mechanism model and solved in Section 5.2.

5.2. Numerical Analysis. Based on the improved residual profit-sharing coordination mechanism established above, the bargaining power coefficients of each decision maker in the Nash negotiation model are calculated as follows: 
TABLE 2: The decisions after interest coordination under different bargaining power coefficients.

\begin{tabular}{|c|c|c|c|c|c|c|c|c|c|c|c|}
\hline & $p^{h d *}$ & $p_{i}^{h d *}$ & $p_{s}^{h d *}$ & $e^{h d *}$ & $s^{h d *}$ & $w^{h d *}$ & $\Pi_{r}^{h d *}$ & $\Pi_{m}^{h d *}$ & $\Pi_{i}^{h d *}$ & $\Pi_{s}^{h d *}$ & $\Pi^{h d *}$ \\
\hline$\eta$ & 34.48 & 18.43 & 16.48 & 43.01 & 21.70 & 6.45 & 985.00 & 534.91 & 119.17 & 79.30 & 1718.4 \\
\hline$\tilde{\tilde{\eta}}$ & 34.48 & 18.85 & 18.42 & 43.01 & 21.70 & 5.03 & 1078.3 & 416.16 & 25.86 & 198.05 & 1718.4 \\
\hline $\bar{\eta}$ & 34.48 & 18.71 & 17.59 & 43.01 & 21.70 & 5.84 & 1018.9 & 484.02 & 68.27 & 147.16 & 1718.4 \\
\hline
\end{tabular}

Note: $\eta$ and $\tilde{\eta}$, respectively, represent the bargaining power coefficients calculated by the Nash negotiation model and minimum core method. $\bar{\eta}$ represents the average of the two bargaining power coefficients above.

$$
\begin{aligned}
\eta_{m} & =0.30 \\
\eta_{r} & =0.47 \\
\eta_{i} & =0.12, \\
\eta_{s} & =\left(1-\eta_{m}-\eta_{r}-\eta_{i}\right)=0.11 .
\end{aligned}
$$

By solving the minimum core method model, the bargaining power coefficients of each decision maker can be obtained as follows:

$$
\begin{aligned}
\tilde{\eta}_{m} & =0.16, \\
\tilde{\eta}_{r} & =0.60, \\
\tilde{\eta}_{i} & =0.01, \\
\tilde{\eta}_{s} & =\left(1-\tilde{\eta}_{m}-\tilde{\eta}_{r}-\tilde{\eta}_{i}\right)=0.23 .
\end{aligned}
$$

By averaging the bargaining power coefficients from the Nash negotiation model and minimum core method, the corrected bargaining power coefficients are as follows:

$$
\begin{gathered}
\bar{\eta}_{m}=\frac{\eta_{m}+\widetilde{\eta}_{m}}{2}=0.24, \\
\bar{\eta}_{r}=\frac{\eta_{r}+\widetilde{\eta}_{r}}{2}=0.53, \\
\bar{\eta}_{i}=\frac{\eta_{i}+\widetilde{\eta}_{i}}{2}=0.06, \\
\bar{\eta}_{s}=\frac{\eta_{s}+\widetilde{\eta}_{s}}{2}=0.17 .
\end{gathered}
$$

In order to compare and analyze the rationality of the above three bargaining power coefficients and the fairness of interest distribution, this paper substitutes the above three bargaining power coefficients into the improved residual profit-sharing coordination model, respectively, for solution. Through calculating, we can get the optimal decisions after interest coordination. And the profits of each decision maker under different bargaining power coefficients are shown in Table 2.

After interest coordination, the profits of each decision maker in the decentralized decision-making mode are greatly improved, and the profit level under the centralized decisionmaking mode is realized. At the same time, the profit gap between the decision makers in the supply chain is gradually narrowed, and the variation coefficient of the profit of each decision maker before interest coordination is 1.23.

If the bargaining power coefficient of the Nash negotiation model is adopted, the variation coefficient of profit of
TABLE 3: Profit growth rates of decision makers after interest coordination.

\begin{tabular}{cccccc}
\hline & $\Pi_{r}^{h d *}$ & $\Pi_{m}^{h d *}$ & $\Pi_{i}^{h d *}$ & $\Pi_{s}^{h d *}$ & $\Pi^{h d *}$ \\
\hline & 985.00 & 534.91 & 119.17 & 79.30 & 1718.4 \\
& $(73.00 \%)$ & $(90.73 \%)$ & $(585.67 \%)$ & $(2579.05 \%)$ & \\
$\tilde{\eta}$ & 1078.3 & 416.16 & 25.86 & 198.05 & 1718.4 \\
& $(89.39 \%)$ & $(48.39 \%)$ & $(48.79 \%)$ & $(6590.88 \%)$ & \\
$\bar{\eta}$ & 1018.9 & 484.02 & 68.27 & 147.16 & 1718.4 \\
\hline
\end{tabular}

Note: the figures in brackets represent the profit growth rate of each decision maker after coordination.

each decision maker after the above interest coordination is 0.99. When the bargaining power coefficient of the minimum core method is adopted, the variation coefficient of profit of each decision maker after interest coordination is 1.07. When the modified bargaining power coefficient is adopted, the variation coefficient of profit of each decision maker after interest coordination is 1.01 .

At the same time, after interest coordination with the above three bargaining power coefficients, the profit growth rates of each decision maker are shown in Table 3. It can be concluded that when the bargaining power coefficient of the Nash negotiation model is adopted, the profit growth rates of each decision maker are more uniform after coordination.

In summary, using the bargaining power coefficient of the Nash negotiation model, the variation coefficient in the profit of each decision maker is smaller, the profit growth rates are relatively balanced, and the variation coefficient of profit growth rates is 1.43 . The variation coefficient of profit growth rates of each decision maker is 1.93, using the bargaining power coefficient of the minimum core method, while the variation coefficient of profit growth rates of each decision maker is 1.78 using the average bargaining power coefficient. Therefore, compared with the other two bargaining power coefficients, the bargaining power coefficient of the Nash negotiation model not only increases the profits of each decision maker in the supply chain but also ensures the fairness of interest distribution to a certain extent. Therefore, the optimal decisions and profit value of each decision maker calculated by this coordination mechanism can be used as an ideal interest coordination scheme.

\section{Conclusion}

This paper takes the dual-channel supply chain system embedded by two-echelon logistics service providers as the object, investigating the optimal decisions and profits of each decision maker in the centralized and decentralized 
decision-making modes under the dominance of the retailer. It analyzes the influence of retail price sensitivity coefficient of online and offline channels, consumers' loyalty to online channels, and sensitivity coefficient of cross-service level on the optimal decisions of supply chain. Then, an improved residual profit-sharing coordination mechanism is designed based on the decentralized decision-making mode, which realizes the interest coordination of the whole dual-channel supply chain system.

The research shows that, in the decentralized decisionmaking mode, cross-service level sensitivity coefficient $\mu$ has a negative impact on the optimal product price, service price, service level, and profits of the retailer, manufacturer, LSI, and supply chain system. The profit of FLSP increases first and then decreases with the increase of $\mu$. At the same time, the profits of each decision maker in PSC and the total profit of supply chain decrease with the increase of $\beta_{1}$ (retail price sensitivity coefficient of online channel) and $\beta_{2}$ (retail price sensitivity coefficient of offline channel). When $\beta_{1}>\beta_{2}$, the profit of FLSP decreases with the increase of $\beta_{1}$ and increases with the increase of $\beta_{2}$; when $\beta_{1}<\beta_{2}$, the profit of FLSP first increases and then decreases with the increase of $\beta_{1}$ and $\beta_{2}$. In other words, the relative size of the price sensitivity coefficient of online and offline channels will have an inconsistent impact on the profit of FLSP, while it has a consistent impact on the profits of other decision makers. The profits of the retailer and the whole supply chain system are more elastic to $\beta_{2}$ than to $\beta_{1}$. The increase of consumers' loyalty $\theta$ to the online channel will increase the demand of the online channel and the profit of LSI, while the profit of FLSP will increase first and then decrease with the increase of $\theta$. In short, the profit of FLSP fluctuates greatly with the change of sensitivity coefficient. In other words, it is difficult for FLSP in a subordinate position to guarantee its interest in the entire supply chain system. In the decentralized decision-making mode, the price elasticity of the offline comprehensive experience service level is greater than 1 , while in the centralized decision-making mode, the price elasticity is affected by the difference between sensitivity coefficients of the offline comprehensive experience service level and crossservice level.

In order to maximize the profit of the entire supply chain system in the decentralized decision-making mode and achieve a reasonable profit distribution among the decision makers, this paper designs an improved residual profit sharing coordination mechanism that fully considers the bargaining power of each participant. Based on the Nash negotiation model and minimum core method, the bargaining power coefficients are, respectively, calculated, and the modified bargaining power coefficient is obtained by averaging the two. On this basis, the above three bargaining power coefficients are introduced into the residual profit-sharing coordination mechanism model for solving. The results show that when the bargaining power coefficient of the Nash negotiation model is adopted, the variation coefficient of profits of each decision maker is smaller and the profit growth rates are more uniform after interest coordination.

The limitations of this study lie in the following aspects. First, this paper only discusses one LSI and one FLSP, but in reality, there is also the case that one LSI integrates multiple FLSPs. Therefore, multiple FLSPs can be considered to provide logistics service for LSI simultaneously in the subsequent research, so as to study the optimal decisions and interest coordination mechanism under this structure. Second, this paper assumes that the market demand function is linear, but in reality, the market demand function may show a trend of nonlinear change under the comprehensive influence of many factors. Therefore, it can also study the optimal decisions in the case of nonlinear demand function. Third, this article focuses on the decision optimization problem led by retailers. In the future, it will be valuable to study decision optimization based on manufacturer-led and LSI-led situations, making a comparative analysis with the retailer-led situation, which may draw more valuable conclusions.

\section{Data Availability}

The data used to support the findings of this study are available from the corresponding author upon request.

\section{Conflicts of Interest}

The authors declare no conflicts of interest.

\section{Acknowledgments}

This work was supported by the General Project of $\mathrm{Hu}$ manities and Social Sciences of China Education Ministry (Grant no. 20YJA630090), Inner Mongolia Social Science Fund Project (Grant no. 19B04), Key Project of Social Science Fund of Inner Mongolia Agricultural University (Grant no. 2017ZD4), and Project of Inner Mongolia Rural Pastoral Development Research Institute.

\section{References}

[1] H. Voordijk, "Physical distribution costs in construction supply chains: a systems approach," International Journal of Logistics Systems and Management, vol. 7, no. 4, pp. 456-471, 2010.

[2] J. Song, Y. Yin, and Y. Huang, "A coordination mechanism for optimizing the contingent-free shipping threshold in online retailing," Electronic Commerce Research and Applications, vol. 26, pp. 73-80, 2017.

[3] J. Yu, N. Subramanian, K. Ning, and D. Edwards, "Product delivery service provider selection and customer satisfaction in the era of internet of things: a Chinese e-retailers' perspective," International Journal of Production Economics, vol. 159, pp. 104-116, 2015.

[4] O. Perdikaki, D. X. Peng, and G. R. Heim, "Impact of customer traffic and service process outsourcing levels on e-retailer operational performancefic and service process outsourcing levels on E-retailer operational performance," Production and Operations Management, vol. 24, no. 11, pp. 1794-1811, 2015.

[5] X.-F. Shao, "Free or calculated shipping: impact of delivery cost on supply chains moving to online retailing," International Journal of Production Economics, vol. 191, pp. 267-277, 2017. 
[6] L. Shu, S. Qu, and Z. Wu, "Supply chain coordination with optimal pricing and logistics service decision in online retailing," Arabian Journal for Science and Engineering, vol. 45, no. 3, pp. 2247-2261, 2020.

[7] J. J. Zhang and Q. L. Zhao, "Research on the transformation and upgrading of circulation supply chain business model driven by new retailing," Journal of Business Economics, vol. 11, pp. 5-15, 2018.

[8] N. N. Yan, X. Y. Huang, and B. Liu, "Dual-source channel master-slave countermeasure model for supply chain in E-market environment," Chinese Journal of Management Science, vol. 3, pp. 98-102, 2007.

[9] P. Zhang, Y. He, and C. Shi, "Retailer's channel structure choice: online channel, offline channel, or dual channels?fline channel, or dual channels?" International Journal of Production Economics, vol. 191, pp. 37-50, 2017.

[10] P. Zhang, Y. He, and X. Zhao, "“Preorder-online, pickup-instore" strategy for a dual-channel retailer," Transportation Research Part E: Logistics and Transportation Review, vol. 122, pp. 27-47, 2019.

[11] H. Liu, S. Sun, M. Lei, H. Deng, and G. K. Leong, "The impact of retailers' alliance on manufacturer's profit in a dualchannel structurefit in a dual-channel structure," International Journal of Production Research, vol. 55, no. 22, pp. 6592-6607, 2017.

[12] J. Lin and J. Wang, "Research on channel decision making of manufacturers in heterogeneous dual channel supply chain," Chinese Journal of Management Science, vol. 26, no. 6, pp. 72-84, 2018.

[13] Y. Cao, C. Q. Yi, and G. Y. Wan, "dual-channel supply chain inventory competition and promotion strategies based on "Free-riding" behavior," Chinese Journal of Management Science, vol. 27, no. 7, pp. 106-115, 2019.

[14] J. Zhou, R. Zhao, and W. Wang, "Pricing decision of a manufacturer in a dual-channel supply chain with asymmetric information," European Journal of Operational Research, vol. 278, no. 3, pp. 809-820, 2019.

[15] B. Yan, T. Wang, Y.-p. Liu, and Y. Liu, "Decision analysis of retailer-dominated dual-channel supply chain considering cost misreporting," International Journal of Production Economics, vol. 178, pp. 34-41, 2016.

[16] L. L. Ren, Y. He, and H. F. Song, "Price and service competition of dual-channel supply chain with consumer returns," Discrete Dynamics in Nature and Society, 2014.

[17] Y. He, H. Huang, and D. Li, "Inventory and pricing decisions for a dual-channel supply chain with deteriorating products," Operational Research, vol. 20, no. 3, pp. 1461-1503, 2020.

[18] Z.-Z. Zhang, Z.-J. Wang, and L.-W. Liu, "Retail services and pricing decisions in a closed-loop supply chain with remanufacturing," Sustainability, vol. 7, no. 3, pp. 2373-2396, 2015.

[19] P. He, Y. He, and H. Xu, "Channel structure and pricing in a dual-channel closed-loop supply chain with government subsidy," International Journal of Production Economics, vol. 213, pp. 108-123, 2019.

[20] L. Wang, H. Song, and Y. Wang, "Pricing and service decisions of complementary products in a dual-channel supply chain," Computers \& Industrial Engineering, vol. 105, pp. 223-233, 2017.

[21] A. Ranjan and J. K. Jha, "Pricing and coordination strategies of a dual-channel supply chain considering green quality and sales effort," Journal of Cleaner Production, vol. 218, no. 2, pp. 409-424, 2019.
[22] H. Liu, Z. P. Wang, and T. Y. Li, "Multi-channel supply chain pricing strategy," China Business and Market, vol. 6, pp. 61-71, 2017.

[23] X. Pu, L. Gong, and X. Han, "Consumer free riding: coordinating sales effort in a dual-channel supply chain," Electronic Commerce Research and Applications, vol. 22, no. 1, pp. 1-12, 2017.

[24] L. Kong, Z. Liu, Y. Pan, J. Xie, and G. Yang, "Pricing and service decision of dual-channel operations in an $\mathrm{O} 2 \mathrm{O}$ closedloop supply chain," Industrial Management \& Data Systems, vol. 117, no. 8, pp. 1567-1588, 2017.

[25] X. Yu and X. Ren, "The impact of food quality information services on food supply chain pricing decisions and coordination mechanisms based on the O2O E-commerce mode," Journal of Food Quality, vol. 2018, no. 4, pp. 1-18, 2018.

[26] S. Subrata, "Channel characteristics and coordination in three-echelon dual-channel supply chain," International Journal of Systems Science, vol. 46, no. 3, pp. 740-754, 2016.

[27] B. Zheng, C. Yang, J. Yang, and M. Zhang, "Dual-channel closed loop supply chains: forward channel competition, power structures and coordination," International Journal of Production Research, vol. 55, no. 12, pp. 3510-3527, 2017.

[28] Y. W. Zhou, J. S. Guo, and W. H. Zhou, "Pricing/service strategies for a dual-channel supply chain with free riding and service-cost sharing," International Journal of Production Economics, vol. 196, no. 11, pp. 98-210, 2018.

[29] A. Amin and H. Jafar, "Transshipment contract for coordination of a green dual-channel supply chain under channel disruption," Journal of Cleaner Production, vol. 223, pp. 596-609, 2019.

[30] Y. He, P. Zhang, and Y. Yao, "Unidirectional transshipment policies in a dual-channel supply chain," Economic Modelling, vol. 40, pp. 259-268, 2014.

[31] Y. Dai, Y. Gao, H. Gao, and H. Zhu, "Real-time pricing scheme based on Stackelberg game in smart grid with multiple power retailers," Neurocomputing, vol. 260, pp. 149-156, 2017.

[32] L. Jiang, Y. Wang, and D. Liu, "Logistics cost sharing in supply chains involving a third-party logistics provider," Central European Journal of Operations Research, vol. 24, no. 1, pp. 207-230, 2016.

[33] A. Dumrongsiri, M. Fan, A. Jain, and K. Moinzadeh, "A supply chain model with direct and retail channels," European Journal of Operational Research, vol. 187, no. 3, pp. 691-718, 2008.

[34] W. Shang and L. Yang, "Contract negotiation and risk preferences in dual-channel supply chain coordination," International Journal of Production Research, vol. 53, no. 16, pp. 4837-4856, 2015.

[35] Y. Ernst, "Global online retailing report: survey findings," Electronic Retailing \& E-Marketing, vol. 10, no. 5, pp. 1-5, 2000.

[36] R. H. Niu, X. Zhao, I. Castillo et al., "Pricing and inventory strategies for a two-stage dual-channel supply chain," Asia Pacific Journal of Operational Research, vol. 29, no. 1, pp. 340-409, 2012.

[37] S. K. Mukhopadhyay, X. Zhu, and X. Yue, "Optimal contract Design for mixed channels under information asymmetry," Production and Operations Management, vol. 17, no. 6, pp. 641-650, 2008.

[38] B. Dan, G. Xu, and C. Liu, "Pricing policies in a dual-channel supply chain with retail services," International Journal of Production Economics, vol. 139, no. 1, pp. 312-320, 2012.

[39] J. Gao, X. Wang, Q. Yang, and Q. Zhong, "Pricing decisions of a dual-channel closed-loop supply chain under uncertain 
demand of indirect channel," Mathematical Problems in Engineering, vol. 2016, pp. 1-13, 2016.

[40] J. Li, Z. Wang, B. Jiang, and T. Kim, "Coordination strategies in a three-echelon reverse supply chain for economic and social benefitfit," Applied Mathematical Modelling, vol. 49, no. 9, pp. 599-611, 2017.

[41] P. Brojeswar, S. S. Shib, and C. Kripasindhu, "Two-echelon manufacturer-retailer supply chain strategies with price, quality, and promotional effort sensitive demand," International Transactions in Operational Research, vol. 22, pp. 1071-1095, 2015. 